1997 Update for the Applications Guide to Vehicle SNM Monitors

Rob L. York

Paul E. Fehlau 



\section{DISCLAMMER}

Portions of this document may be illegible in electronic image products. Images are produced from the best available original document. 


\section{Table of Contents}

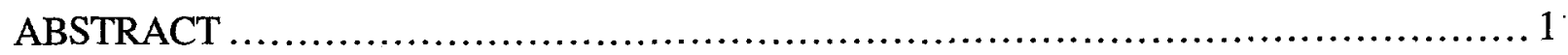

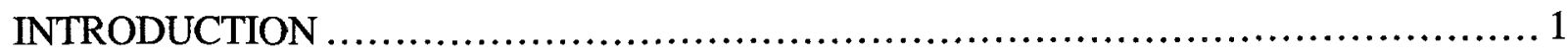

PART I: A REVIEW OF THE BASICS OF VEHICLE SNM MONITORING................2

I. THE ELEMENTS OF RADIATION MONITORING .................................... 2

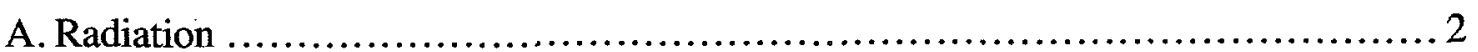

B. Radiation Detectors........................................................ 2

C. Radiation Monitoring ..................................................... 3

II. CHARACTERISTICS OF SNM MONITORS ....................................... 4

A. Automatic SNM Monitors ................................................. 4

B. Hand-Held Monitors ........................................................ 5

III. INTRODUCTION TO VEHICLE SNM MONITORS ............................... 6

IV. AN OVERVIEW OF THE VEHICLE SNM MONITORS $\ldots \ldots \ldots \ldots \ldots \ldots \ldots \ldots \ldots \ldots \ldots \ldots . . \ldots$

A. Hand-Held Monitors ........................................................ 7

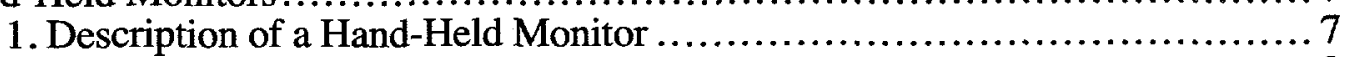

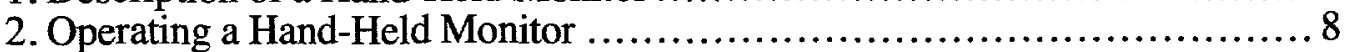

3. Hand-Held Monitor Cost and Availability .................................. 9

B. Vehicle SNM Portal Monitors ............................................ 9

1. Description of a Vehicle SNM Portal Monitor....................................9

2. Vehicle Portal Operation ................................................. 11

3. Vehicle Portal Cost and Availability .................................... 11

C. Vehicle SNM Monitoring Stations ............................................ 12

1. Description of a Vehicle SNM Monitoring Station............................ 12

2. Vehicle Monitoring Station Operation .................................. 15

3. Vehicle Monitoring Station Costs and Availability .......................... 16

D. Neutron-Detection-Based SNM Vehicle Portal Monitors.......................... 16

1. Description of a Neutron-Detection-Based Vehicle Portal .................. 16

2. Neutron-Detection-Based Vehicle Portal Operation.......................... 17

3. Neutron-Detection-Based Vehicle Portal Cost and Availability .............. 18

PART II: TECHNICAL INGREDIENTS OF VEHICLE SNM MONITORING ............. 18

I. FACTORS THAT AFFECT VEHICLE SNM MONITOR PERFORMANCE ............... 18

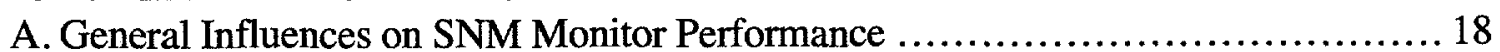

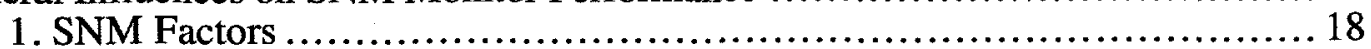

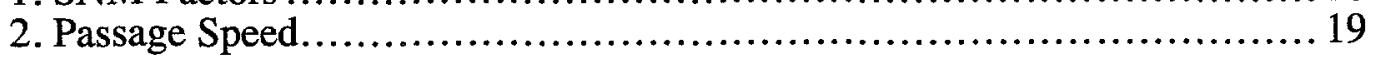

B. Particular Influences on Performance: Pedestrian/Vehicle Monitor Differences ...... 20

1. Background Reduction During Occupancy ................................. 20

2. Source Attenuation by Vehicles ......................................... 21

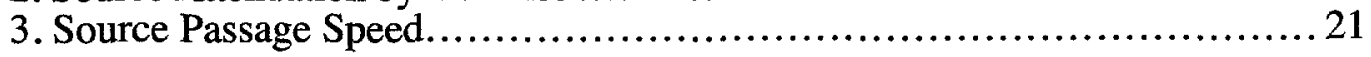




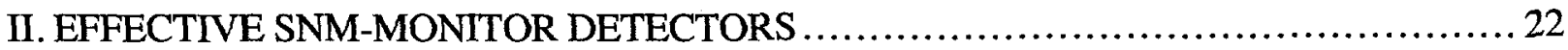

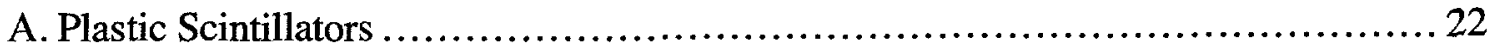

B. Neutron Chamber Detectors................................................ 23

III. EFFECTIVE METHODS FOR MAKING MONITORING DECISIONS ................. 25

A. Alarm Thresholds ............................................................ 25

B. A Comparison of Single- and Multiple-Measurement Methods.....................26

C. The Moving-Average (MA) Method ......................................... 27

D. The Sequential-Probability-Ratio Test (SPRT) Method ......................... 28

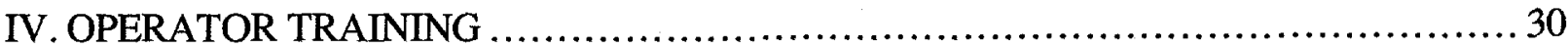

V. CALIBRATION, MAINTENANCE, AND TESTING ................................. 31

A. Applications Guidance ....................................................... 31

B. Calibration Guidance............................................................. 31

C. Testing Procedure Guidance .................................................. 32

PART II: VEHICLE SNM MONITOR CATALOG .................................... 32

I. VEHICLE SNM MONITOR SENSITIVITY CATEGORIES ............................ 33

A. Historical Performance Categories .............................................. 33

B. Recent Performance Estimates ............................................... 34

1. Performance Estimates for a Neutron Vehicle Portal Monitor ..................34

2. Performance Estimates for an Expanded SNM Vehicle-Portal ............... 34

II. COMMERCIALLY AVAILABLE VEHICLE SNM MONITORS ......................... 36

A. Hand-Held Monitors ............................................................... 36

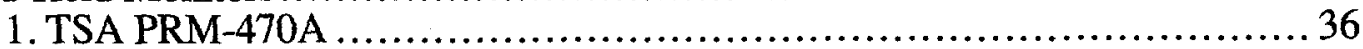

B. Vehicle SNM Portal Monitors ............................................... 37

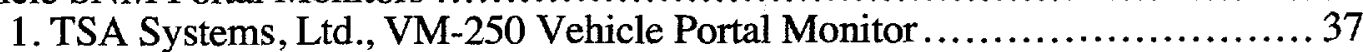

2. Canberra JPM-12A Vehicle Portal Monitor................................ 38

3. Canberra JPM-31A Neutron Vehicle Portal Monitor ........................ 39

C. Related Vehicle Portal Monitors .............................................. 40

1. Ludlum Measurements, Inc., 3500 Gate Monitor .......................... 40

2. Bicron Corp. ASM 6000 Steel Scrap Monitors ............................. 40

D. Vehicle SNM Monitoring Stations .......................................... 41

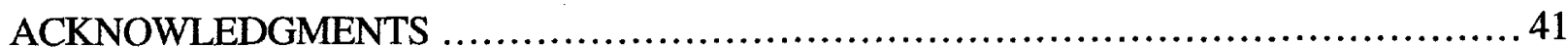

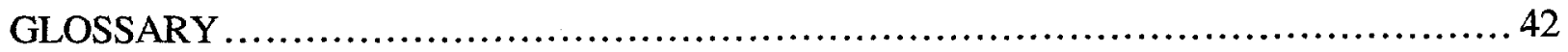




\title{
1997 UPDATE FOR THE APPLICATIONS GUIDE TO VEHICLE SNM MONITORS
}

by

\author{
Rob L. York and Paul E. Fehlau
}

\begin{abstract}
Ten years have elapsed since the publication of our original applications guide to vehicle SNM monitors. ${ }^{1}$ During that interval, use of automatic vehicle monitors has become more commonplace, and formal procedures for monitor upkeep and evaluation have become available. New concepts for vehicle monitoring are being explored, as well. This update report reviews the basics of vehicle SNM monitoring, discusses what is new in vehicle SNM monitoring, and catalogs the vehicle SNM monitors that are commercially available.
\end{abstract}

\section{INTRODUCTION}

Vehicle special nuclear material (SNM) monitors are radiation detection systems that sense gamma rays and neutrons emitted by SNM as an effective means to quickly search vehicles for SNM. The monitors range from small hand-held units to large automatic monitoring stations. Although vehicle monitors are not as familiar to us as pedestrian SNM monitors, they now are in routine use at many protected area boundaries. Their purpose is to provide the outermost layer of protection against the theft of SNM.

In recent years, there have been related applications of vehicle SNM monitors to such problems as keeping radioactive materials out of landfills, keeping radioactive materials out of scrap used in steel production, and keeping radioactive materials from crossing national boundaries.

This guide serves as a review of the basic technology for SNM monitoring, and for vehicle SNM monitoring technology in particular, as it was introduced in our earlier SNM monitor applications guides. ${ }^{2-4}$ Our hope is to point out the important essentials of SNM monitoring in simple terms, and we also wish to introduce the new monitoring technology and procedures that have evolved in recent years. The report is organized in parts that provide an overview, a description of new material, and a catalog of available monitors.

1 P. E. Fehlau, “An Applications Guide to Vehicle SNM Monitors," Los Alamos National Laboratory report LA10912-MS (March 1987).

2 P. E. Fehlau, "An Applications Guide to Pedestrian SNM Monitoring," Los Alamos National Laboratory report LA-10633-MS (February 1986).

3 P. E. Fehlau, "An Applications Guide to Vehicle SNM Monitors," Los Alamos National Laboratory report LA10912-MS (March 1987).

4 Paul E. Fehlau, "1990 Update for the Applications Guide to Pedestrian SNM Monitors," Los Alamos National Laboratory report LA-11971-MS (November 1990). 
Finally, a brief glossary of technical terms is included at the end of the report to enable readers to find meaning in unfamiliar terms.

\section{PART I}

\section{A REVIEW OF THE BASICS OF VEHICLE SNM MONITORING}

Vehicle SNM monitoring involves detecting significant changes in radiation intensity when a vehicle occupies a monitor. In this part of the report, you will find brief descriptions of radiation, radiation detectors, and radiation monitors, as well as more detailed descriptions of the various types of vehicle SNM monitors.

\section{THE ELEMENTS OF RADIATION MONITORING}

\section{A. Radiation}

Radioactive materials are ones that comprise, in part or entirely, atoms that are unstable and disintegrate at some rate into other particles and other forms of energy, such as gamma rays. SNM, for example highly enriched uranium and plutonium, are radioactive materials, and they emit radiation that can serve to indicate their presence. Uranium emits gamma rays (electromagnetic radiation, such as light) and plutonium emits both gamma rays and neutrons (neutral particles). The rate at which these substances emit radiation is an important factor in how easily they can be sensed. Plutonium is far more radioactive than uranium, and its much higher rate of emission allows it to be sensed in much smaller quantity than uranium.

\section{B. Radiation Detectors}

To make radiation a practical indicator for SNM, we use radiation detectors to convert radiation into electrical current pulses that can be counted to measure radiation intensity. The way radiation detectors work is, first of all, to intercept the radiation and then to absorb as much of it as possible and convert it to a usable form for counting. The amount of radiation intercepted depends on the detector's size, and converting it depends on physical properties of the detector material.

The major types of detectors used for SNM monitoring are: (1) thallium-activated sodium iodide [ $\mathrm{NaI}(\mathrm{Tl})]$ scintillation detectors that sense gamma rays, (2) plastic scintillators that sense both gamma rays and energetic neutrons, and (3) ${ }^{3} \mathrm{He}$ gas proportional counters that sense lowenergy neutrons.

The scintillators are transparent materials that convert radiation into light pulses that can, in turn, be converted and amplified by a photomultiplier tube into electrical-current pulses.

The ${ }^{3} \mathrm{He}$ gas in proportional counters reacts with low-energy neutrons producing ions that then can be formed into current pulses. Energetic neutrons from spontaneous fission in plutonium are detected after first being slowed to lower energy in a moderating material, such as polyethylene, that surrounds the proportional counters. Moderation to lower energy may also take place in any 
handling fixtures or packaging materials surrounding the plutonium, which further increases its detectability in a well-designed neutron detector.

\section{Radiation Monitoring}

Radiation monitoring is a process whereby radiation detectors continually sense radiation, measure its intensity, and in many cases automatically detect changes in the radiation intensity. Detecting significant changes in radiation intensity is the key to SNM monitoring.

Our natural environment is a source of background neutrons and gamma rays from radioactive materials in the earth and from cosmic rays striking the earth's atmosphere. Radiation monitors measure the count rate produced in the monitor's detectors by background radiation, and the background count rate is often simply referred to as the monitor's "background."

The first, and continuing, requirement for monitoring is to measure background count rates and use them to periodically update an alarm threshold. During monitoring, measurement results will be compared with the alarm threshold to detect significant increases in radiation intensity that may indicate the presence of SNM or other radioactive materials.

SNM monitors use microprocessor-based control for their operation. When the microprocessor receives an indication that the monitor is occupied, it begins monitoring measurements and compares the results to the most recent, pre occupancy, alarm threshold using one of a number of possible analysis techniques. The goal for each technique is to effectively group the monitoring results to best enhance weak signals from SNM and provide the largest possible measurement result and greatest sensitivity for the monitor.

Microprocessor techniques for monitoring use one of a number of equivalent analysis methods that are discussed in greater detail in Sec. III of Part II of this report. The most straightforward example of these is the moving-average method used in drive-through vehicle portal monitors that makes many short monitoring measurements and records the results for a period of time, whether or not monitoring is in progress. Whenever monitoring is called for, the microprocessor continues making and recording measurement results, but it also sums each new result with a chosen number of the most recently recorded results. As monitoring continues, each new sum is compared with the alarm threshold, and an alarm is sounded if any sum equals or exceeds the threshold.

The moving average just described is a familiar method used in stock market analysis, and its value is in grouping results to more precisely detect a trend. For monitoring, the method is tailored to the expected time that a signal from SNM passing through the monitor would be present. If the match is good, then, during monitoring, one of the moving average sums is likely to contain the largest possible number of counts from SNM passing through the monitor, thus ensuring the highest possible sensitivity for the monitor. Figure 1 illustrates a monitor's count rate and the related four-point moving averages of the count rate. 


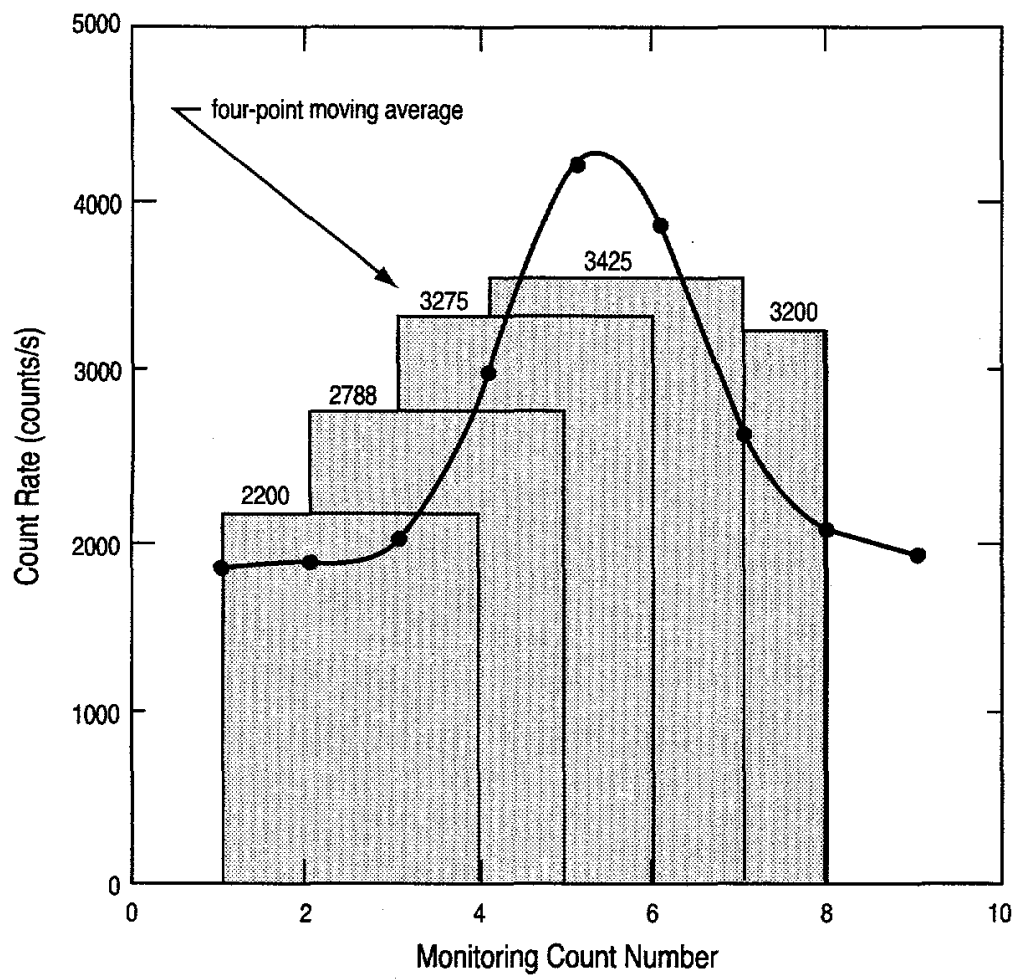

Fig. 1 An exaggerated view of a monitors count rate profile as an SNM source passes through, and the related fourpoint moving averages of the count rate (in counts/s).

The cost of using the moving average and other methods is that making additional monitoring comparisons will increase the nuisance alarm rate that is caused by statistical variation in the measurement process. Hence attaining a desired nuisance alarm rate would require that the alarm threshold be increased a bit over what would be required for a simpler method using few comparisons per passage. However, the gain in sensitivity from grouping far exceeds any decrease in sensitivity from increasing the alarm threshold in these methods. Hence, making use of the moving average or similar methods is essential for obtaining the best possible sensitivity. ${ }^{5}$

\section{CHARACTERISTICS OF SNM MONITORS}

\section{A. Automatic SNM Monitors}

SNM monitors may be one of two types of stationary, automatic SNM portal monitors, or they may be one of the small, readily portable, hand-held SNM monitors. The major difference between automatic and hand-held monitors is that the latter are small and must be used by security personnel who conduct a search for SNM, whereas the former automatically conduct the monitoring without additional help as long as an alarm does not occur. In either case, if alarms do occur, the hand-held monitor used by trained security personnel is the best bet for additional searching to find the cause.

The automatic SNM monitors most often employ a simple arrangement of radiation detectors, usually plastic scintillators, to form a portal through which a pedestrian or vehicle passes while

5 W. H. Chambers, H. F. Atwater, P. E. Fehlau, R. D. Hastings, C. N. Henry, W. E. Kunz, T. E. Sampson, T. H. Whittlesey, and G. M. Worth, "Portal Monitor for Diversion Safeguards," Los Alamos Scientific Laboratory report LA-5681 (December 1974). 
being monitored. In a few other cases, monitoring is a longer process and a pedestrian or vehicle must remain stationary in a more elaborate arrangement of detectors while being monitored. Examples of such monitors are the SNM monitoring booth for pedestrians and a vehicle SNM monitoring station for motor vehicles.

During operation, SNM monitors spend most of their time continuously measuring background radiation intensity and periodically using the results to establish alarm thresholds that will be up-tothe-minute when monitoring is called for. Each automatic monitor has some means to sense that an occupant (that is, a person or vehicle) is present to be monitored. If no occupant is present, backgrounds are measured over an interval ranging from a few seconds to minutes, depending on the application, and then a new average background and alarm threshold are calculated. Monitors requiring longer monitoring and background intervals sometimes use a moving-average to partially update their alarm threshold more frequently for better timeliness.

When a monitor senses that a person or vehicle is present in a pass-through portal monitor, the monitor can begin monitoring with stored data that was recorded during the occupant's approach. As monitoring continues and new measurements are stored, the most recent ones are used for monitoring. Monitoring ceases when the occupant has passed through the sensitive region of a portal monitor. In a monitoring booth or vehicle monitoring station the situation is a little different, and there may be a delay before monitoring begins to allow the occupant to fully occupy the monitor. In this case monitoring continues until a decision can be reached before the occupant is allowed to depart.

During occupancy, monitoring decisions are made by comparing detector count rate measurement results with the current alarm threshold. A decision that the results equal or exceed the alarm threshold triggers an alarm. The number of decisions that need to be made is different in the two different types of monitor. Only one decision needs to be made in a monitoring booth or station where the occupant is stationary, but several background (and possibly one alarm) decisions are usually necessary in a pass-through portal. The portals must continue to monitor for as long as necessary as each occupant passes through at a normal pace.

\section{B. Hand-Held Monitors}

Hand-held monitors are small SNM monitors that are similar to the automatic monitors, but they depend on an operator to conduct a search and to make important decisions. The operator is responsible for manually initiating the background and alarm threshold update process, as needed, in the area where a search will be conducted. The operator also must carefully observe the person or vehicle being monitored and make sure that every location where SNM could be hidden will be searched.

The operator conducts a search by slowly moving a hand-held SNM monitor over any item or person being monitored while listening for alarms. In the process, the monitor must be oriented in a way that points its sensitive end towards possible locations for SNM. If a hand-held monitor should signal an alarm, the cause may be located by moving the hand-held monitor nearby from place to place while listening for repeated alarms. The greatest frequency of repeated alarms will occur near the SNM or other source causing the alarms. If alarms become too frequent to direct the 
course of a search, the monitor's background can be reset nearby to raise the alarm threshold, which reduces the sensitivity and allows pinpointing the location of a strong source of radiation.

If no repeated alarms occur in follow-up searching, the original alarm may have been a nuisance alarm. Nuisance alarms are usually caused by statistical variation in a monitor's measurement results, but they also may result from real changes in background intensity, perhaps caused by movement of radioactive materials or by operation of radiation-producing machinery.

Because the repeated alarms in searching are very significant in monitoring with the hand-held instruments, the alarm thresholds for hand-held monitors can be set much lower than would be set for automatic monitors, where every alarm is significant. The resulting background nuisance alarms at rates up to one per minute, or so, are easily tolerated because they will usually be single alarms and have little impact on searches. This use of repeated alarms and a lower alarm threshold is one reason that hand-held SNM monitors can be much more sensitive than automatic monitors.

Another factor that helps hand-held monitors to achieve high sensitivity is that they can be moved very close to possible locations for SNM when operated by well-trained inspectors. However, the converse is also true; if inspectors are not well trained and motivated, their search effectiveness may be less than average.

The detectors in hand-held monitors now are usually plastic scintillators, but older monitors used $\mathrm{NaI}(\mathrm{Tl})$ scintillators. Lower cost is one reason for using plastic scintillators in commercial SNM monitors at this time. Sensitivity to both gamma rays and neutrons is another reason for preferring plastic scintillators. The added neutron sensitivity of plastic scintillators may allow them to detect plutonium in a container that shields the plutonium gamma-ray emissions. The reason for this is that searching near gamma-ray shielding materials with a hand-held monitor may reduce the monitor's gamma-ray response but the unshielded neutron signal should still be there, perhaps intense enough to permit detection.

\section{INTRODUCTION TO VEHICLE SNM MONITORS}

The primary purpose for vehicle SNM monitoring is to help prevent unauthorized removal of SNM from facilities. At facility material access area (MAA) boundaries where vehicle access is seldom allowed, hand-held SNM monitors are most often used. At facility protected area (PA) boundaries where vehicle access is routine, automatic monitors may be used as part of a layered, or graded, approach to protecting SNM. Related applications for automatic vehicle radiation monitors are now becoming common for such applications as preventing radioactive materials from entering landfills and preventing them being included in scrap materials used for making steel. Another new

application is for entry control at national borders to prevent passage of clandestine nuclear or other radioactive materials.

The two types of automatic vehicle SNM monitor are the simple, drive-through, vehicle portal monitors and the more complex vehicle-monitoring stations, where vehicles park for a short period of time during monitoring. Vehicle-monitoring stations achieve high sensitivity for detecting small amounts of SNM by using an array of large plastic scintillation detectors located close to a vehicle 
and by monitoring for an extended period of time. Vehicle portal monitors use fewer plastic scintillation detectors, and the detectors form a portal for the vehicle to pass through. Another, newer type of vehicle portal uses large neutron-chamber detectors containing ${ }^{3} \mathrm{He}$ gas proportional counters to form a portal for detecting neutrons from plutonium.

Hand-held SNM monitors operated by trained inspectors can substitute for the automatic SNM vehicle monitors when adequate time, equipment, personnel, training, and supervision are available. Hand-held SNM monitors are most valuable, however, for making a follow-up search for SNM after an alarm in an automatic SNM monitor.

Besides equipment and personnel, establishing an SNM monitoring program requires the means and procedures for training operating personnel, testing monitor performance, and periodically maintaining the SNM monitoring equipment. The American Society for Testing and Methods has published several guides covering aspects of these topics (see Sec. V of Part II).

\section{AN OVERVIEW OF THE VEHICLE SNM MONITORS}

\section{A. Hand-Held Monitors}

\section{Description of a Hand-Held Monitor}

Hand-held monitors are the simplest form of vehicle SNM monitor. They usually are small, lightweight packages similar to the one shown in Fig. 2, a TSA Systems model PRM-470A that weighs $1.3 \mathrm{~kg}(2.9 \mathrm{lb})$. The external features of the monitor include a handle, alphanumeric display, alarm sounder, and switches on the front panel.

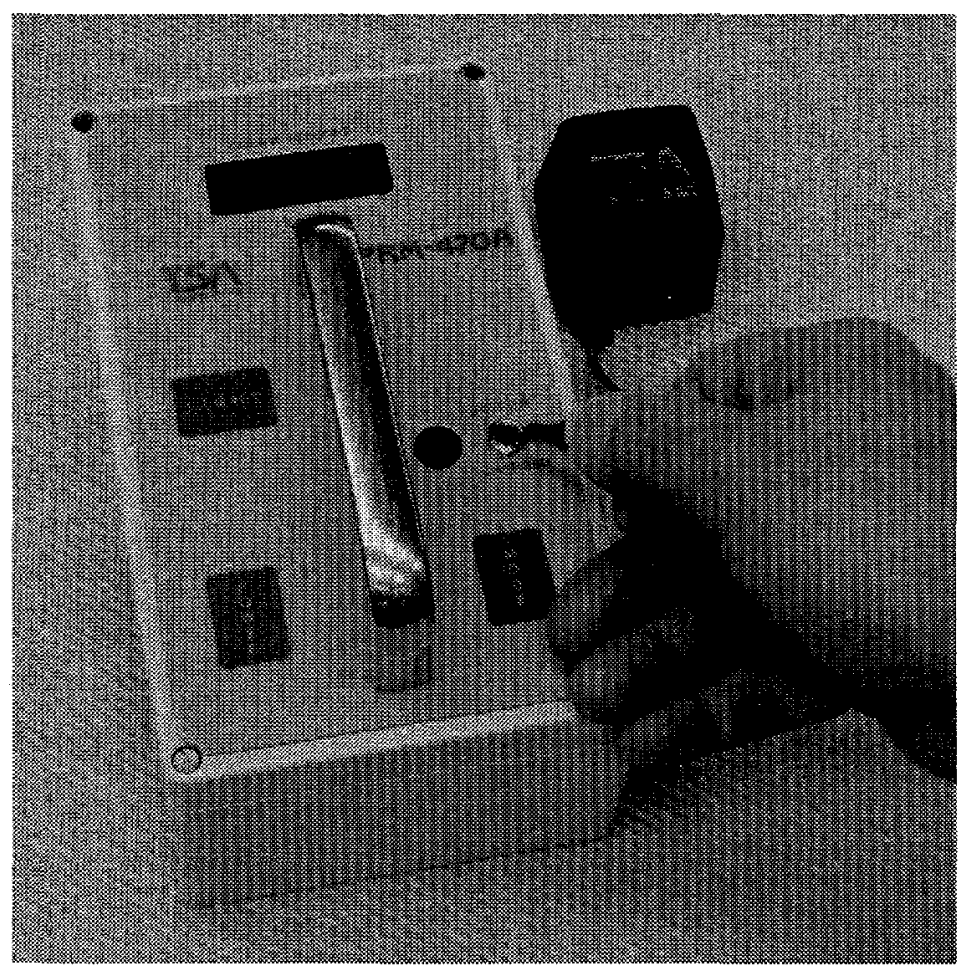

Fig. 2. An outside view of the PRM-470A. 
The contents of the monitor interior shown in Fig. 3 include a radiation detector, 60-hour operating capacity rechargeable battery, battery-operated power supplies, high-voltage and signalconditioning electronics, and a microprocessor.

This monitor's radiation detector is a plastic scintillator (Fig. 3) that is located near the front of the case, below the display, and the detector is sensitive to gamma rays and fast neutrons. Older instruments may have a $\mathrm{NaI}(\mathrm{Tl})$ scintillator and respond only to gamma rays.

The key difference between hand-held SNM monitors and other types of hand-held radiation instruments used for radiation protection is their microprocessor-based detection method. Rather than requiring the operator to watch a display of detector count rate during a search, the microprocessor software detects significant changes in count rate and signals alarms to the operator with an alarm sounder. On demand, the monitor uses its own measurement of background intensity to set an alarm threshold that offers high sensitivity under the present ambient radiation environment. The monitoring method used is the moving-average method described in Sec. III.c of Part II of this report, and it has the capability to achieve high sensitivity during the relatively rapid monitoring that takes place with a hand-held monitor. Counting intervals are typically $50 \mathrm{~ms}$ long for fast response, and as many as eight intervals may be used in the moving average when monitoring at a rate of about $0.5 \mathrm{~m} / \mathrm{s}$ over surfaces where SNM may be located.

\section{Operating a Hand-Held Monitor}

The hand-held monitor is most effective when it is operated by a well-trained and motivated individual. Step-by-step instructions for its use can be found in the Los Alamos User's Manual for the PRM-470A instrument. ${ }^{6}$ In essence, the inspector grasps the instrument so that the display can be read (so the writing is right-side up as in Fig. 2), which ensures that the sensitive end of the monitor is directed away from the inspector and toward the area being searched.

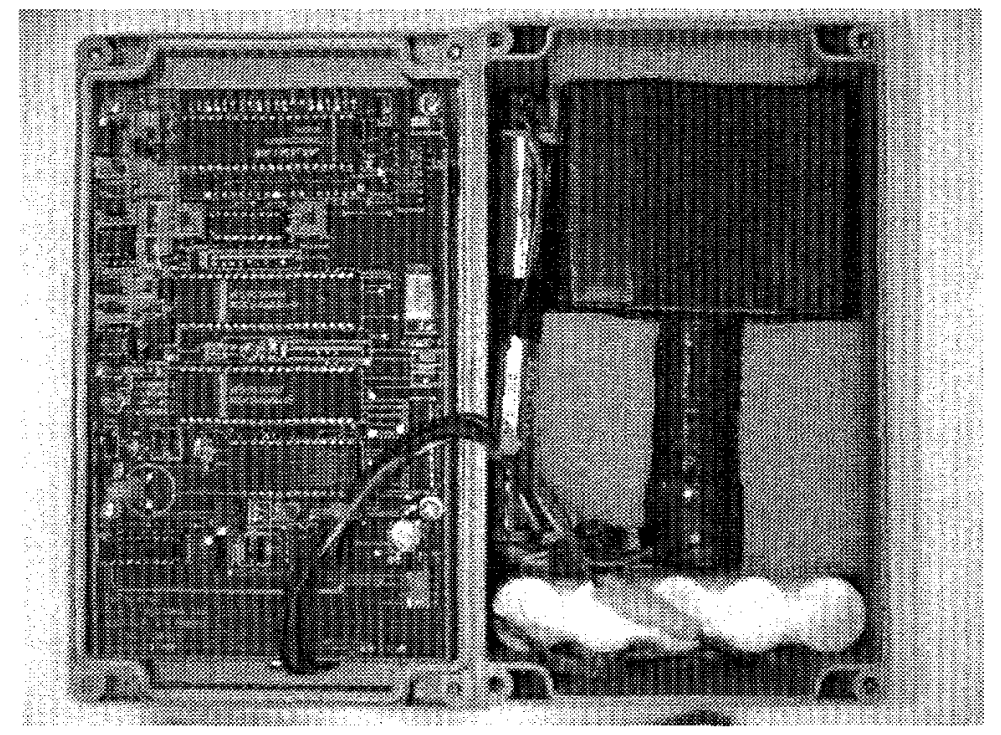

Fig. 3. An inside view of the PRM-470A.

6 Paul E. Fehlau, "User's Manual for the PRM-470A Hand-Held Special Nuclear Material Monitor," Los Alamos National Laboratory document LALP 92-79 (December 1992). 
The next step in using the monitor to search for SNM is for the inspector to reset the background (if necessary). With the recommended version of the monitor's software, Version 1.02 , the monitor is always capable of searching, except for a few moments when the background is measured and the alarm threshold is updated. The inspector simply presses the mode switch, the monitor measures the background and updates the alarm threshold, and then the monitor automatically returns to the monitoring mode. Then searching simply involves moving the monitor over and around items or individuals while keeping the monitor within $0.25 \mathrm{~m}$ (10 in.) of each surface and listening for beeps. Scanning speeds of $0.5 \mathrm{~m} / \mathrm{s}(20 \mathrm{in} . / \mathrm{s})$ may be used.

When the monitor senses a source of radiation, it begins beeping more and more as the monitor approaches the source. Discrete sources can be pinpointed by moving the monitor around to find the strongest response (most frequent beeps).

Remember that the overall effectiveness of hand held monitoring depends on having both an effective monitor and an effective operator. The operator is a variable part of the combination, and proper training and motivation for conducting effective searches is important.

\section{Hand-Held Monitor Cost and Availability}

Hand-held SNM monitor costs have ranged from below $\$ 2000$ to almost $\$ 3000$. These are instruments that meet the performance criteria listed in Appendix I of ASTM C 1237-93.7 The criteria include detecting with probability of 0.5 or greater the passage of $10 \mathrm{~g}$ of $235 \mathrm{U}$ in the form of a metallic sphere as it passes by at a speed of $0.5 \mathrm{~m} / \mathrm{s}(20 \mathrm{in} . / \mathrm{s})$ at a distance of $0.25 \mathrm{~m}(10 \mathrm{in}$.) in a $20 \mu \mathrm{R} / \mathrm{h}$ background environment. Remember that other hand-held radiation detection instruments that are available at lower cost probably lack the combination of both a good radiation detector and a good microprocessor method for sensing the transient radiation signals that are part of rapid hand-held monitoring.

The PRM-470A monitor is the most commonly used, commercially available, hand-held SNM monitor. It is available from TSA Systems, Ltd., of Longmont Colorado. ${ }^{8}$ It's 1995 cost is $\$ 1650$. Older commercially available hand-held SNM monitor designs listed in the original vehicle monitoring guide may still be available. One of these, the TSA Systems HHD-440 is still supported by the manufacturer, but strong sales of the newer PRM-470A have eliminated sales of the HHD-440. The National Nuclear Corp. ${ }^{9}$ HM-3 is still available; it uses a NaI(Tl) detector, discrete logic instead of a microprocessor, and it has a 1995 price of $\$ 2973$.

\section{B. Vehicle SNM Portal Monitors}

\section{Description of a Vehicle SNM Portal Monitor}

Vehicle Portal Monitors are the simplest type of automatic vehicle monitor, and they are very similar to pedestrian SNM portal monitors. The vehicle portal detectors are mounted in cabinets beside a roadway, and the detector cabinets define the portal that a vehicle must pass through while

7 ASTM Standard C 1237-93, "Standard Guide to In-Plant Performance Evaluation of Hand-Held SNM Monitors," American Society for Testing and Materials, 100 Barr Harbor Dr., W. Conshohocken, PA 19428-2959.

8 TSA Systems, Ltd., 1830 Boston Avenue, Longmont, CO 80501 (303-651-6147).

9 National Nuclear Corp., 1904 Colony Street, Mountain View, CA 94043 (405-962-9220). 
being monitored (Fig. 4). The detectors are usually plastic scintillators that are sensitive to gamma rays and fast neutrons. In one special case, the detectors are neutron-detection-based and composed of a hollow polyethylene box containing four neutron proportional counters that is called a neutron-chamber detector.

In related types of vehicle monitoring, such as those for monitoring scrap metal at steel plants, $\mathrm{NaI}(\mathrm{Tl})$ scintillators, plastic scintillators, and other types of detector have all been used for detecting gamma rays from misplaced radiographic sources and other highly radioactive source materials. ${ }^{10}$

The signal-conditioning electronics and microprocessor-based monitor control unit in vehicle portal monitors may be housed in the detector cabinets when they use low-power electronics. In other cases where Nuclear Instrument Module [NIM] or similar electronics operating from line power are used, a separate cabinet or location for the electronics is usually necessary because of the large amount of heat that is generated. Mixed situations also could arise involving low-power signal-conditioning electronics in the detector cabinets and a NIM or other line-power controller, located separately.

An occupancy monitor, such as a passive infrared detector or a traffic-control magnetic loop, may be used to trigger the start of monitoring. When the vehicle portal is occupied, monitoring is continuous until an alarm occurs or the occupancy sensor returns to its unoccupied state.

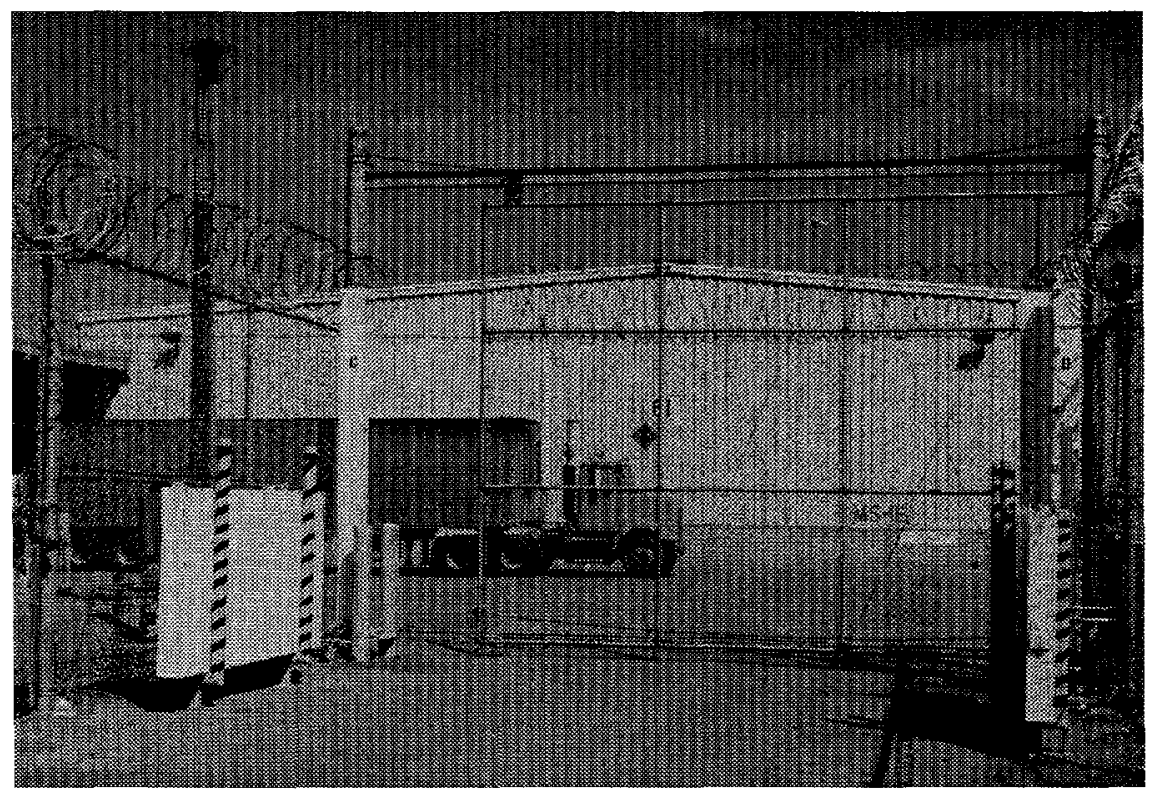

Fig. 4. Two vehicle portal monitors. The narrow white cabinets contain plastic scintillators for detecting highly enriched uranium or plutonium. The large white cabinets are neutron chamber detectors forming a portal for detecting plutonium, even if it is shielded.

10 J. O. Lubenau and J. G. Yusko, "Radioactive Materials in Recycled Metals," Health Physics, Volume 68, Number 4, April 1995. 
Vehicle portals often have a remotely located information panel to inform security inspectors of alarms or lack of alarms during monitoring. Other information, such as suspension of monitoring during high- or low-background conditions can also be displayed, and, in one case, vocally announced with an appropriate message by a speech generator. An alarm-reset switch would also be located on the panel if alarms were not being automatically reset.

\section{Vehicle Portal Operation}

Vehicle portal monitors are fully automatic monitors and require little intervention by a security inspector. They are located where vehicles are slowing to a stop for clearance to enter or exit a protected area. It is best that monitoring be complete before the vehicle reaches the stopping place so that the monitor will be unoccupied during any resolution of alarms.

Often vehicle traps are used at entry stations, and these effectively control speed if the monitor is located at the entrance where a vehicle must stop while a gate is opened, for example as shown earlier in Fig. 4. Then monitoring takes place while the vehicle begins moving into the trap from a standing start. When monitoring is complete, the vehicle is trapped by two closed gates until entry or exit clearance is obtained and the second gate is opened for departure.

When the vehicle portal monitor is unoccupied, background measurements are being made and alarm thresholds are constantly updated. Whenever a vehicle is sensed, monitoring begins. An example of monitoring in vehicle portals is the following. The microprocessor continuously makes measurements of about $0.5-\mathrm{s}$ duration and stores the results, whether or not a vehicle is present. Periodically, the results are used to establish a new average background and alarm threshold. When a vehicle is sensed, monitoring begins, and as each measurement is completed, it is recorded and the sum of the four most recent measurements is compared with the alarm threshold.

As with hand-held monitors, this moving-average method requires a somewhat higher alarm threshold than would be required for making a few single-interval measurements during occupancy. However, the moving average method still achieves a higher sensitivity because it has a much better chance of capturing the greatest possible measurement result.

When alarms occur in vehicle portals, they are best investigated by using a hand-held SNM monitor. The hand held monitors are used to make a thorough inspection of the vehicle as described in the hand-held monitor user's guide (see Ref. 6). If the cause of an alarm cannot be located, the vehicle should be made to back out of the trap and re-enter through the vehicle portal monitor once more. If the automatic monitor alarms again, then the question is whether the monitor is defective or whether the hand-held monitoring was not thorough enough. The safest resolution of the question would be obtained from information gained by both repeating the hand-held monitoring and driving a different but similar vehicle through the automatic monitor.

\section{Vehicle Portal Cost and Availability}

The cost of vehicle SNM portal monitors using plastic scintillators are in the neighborhood of $\$ 20,000$ to $\$ 30,000$. Neutron-detection-based vehicle SNM portal monitors are more costly and 
seldom appear in manufacturer's catalogs. Manufacturers may be able to provide such a monitor as a special item if one is not listed in the catalog section of this report.

The common plastic scintillator monitors are represented by the TSA Systems, Ltd., VM-250 monitor, which is the monitor with narrow white cabinets shown in Fig. 4. Canberra Industries is developing a similar monitor that is described in the catalog section.

The VM-250 monitors are self-contained, and the indicator lights, alarm sounder, and occupancy sensor are mounted to the front door of one or both of the cabinets. The most sensitive application of vehicle portal monitors uses only one control unit for analyzing measurements obtained by summing data from both detector cabinets. This arrangement obtains the highest sensitivity for monitoring a single traffic lane. If high sensitivity is not required, one lane or two traffic lanes through a portal could be monitored by using an independent control unit in each of the detector cabinets. The advantage would be not having to interconnect the cabinets, and the disadvantage is a reduction in sensitivity at the portal center. In one example, a source detected with probability 0.5 at the center of a portal with summed data would be detected with probability of about 0.23 by two independent cabinets.

Vehicle portals can operate with or without a remote information module. The necessary alarm sounder and indicator lamps can be mounted externally on the detector cabinets, or they can be located on a remote module inside an entry-control station, or both options can be used together.

\section{Vehicle SNM Monitoring Stations}

\section{Description of a Vehicle SNM Monitoring Station}

Vehicle SNM monitoring stations are large automatic monitoring systems that have many detectors and use a relatively long monitoring time to thoroughly monitor stationary vehicles. The monitoring station radiation detectors are plastic scintillators that are sensitive to gamma rays and fast neutrons.

The vehicle SNM monitoring station detectors are mounted in arrays that surround the vehicle on at least two sides. The SNM monitoring stations at Los Alamos have three arrays of four detectors located below a vehicle and one array of four located overhead (Fig. 5). The purpose of the distributed arrays of detectors is to achieve the necessary complete coverage of routine vehicles. Very long vehicles can be monitored in stages.

In related types of vehicle monitoring, such as those for monitoring radioactive materials that may be contained in scrap metal entering steel plants, the suspicious region of a vehicle that must be monitored can be limited to the cargo area. As a result, a much simpler detector arrangement suffices; for example, for large trucks, the horizontally oriented detectors shown in Fig. 6 can be adjusted to an appropriate height and the vehicle can slowly be moved through. 


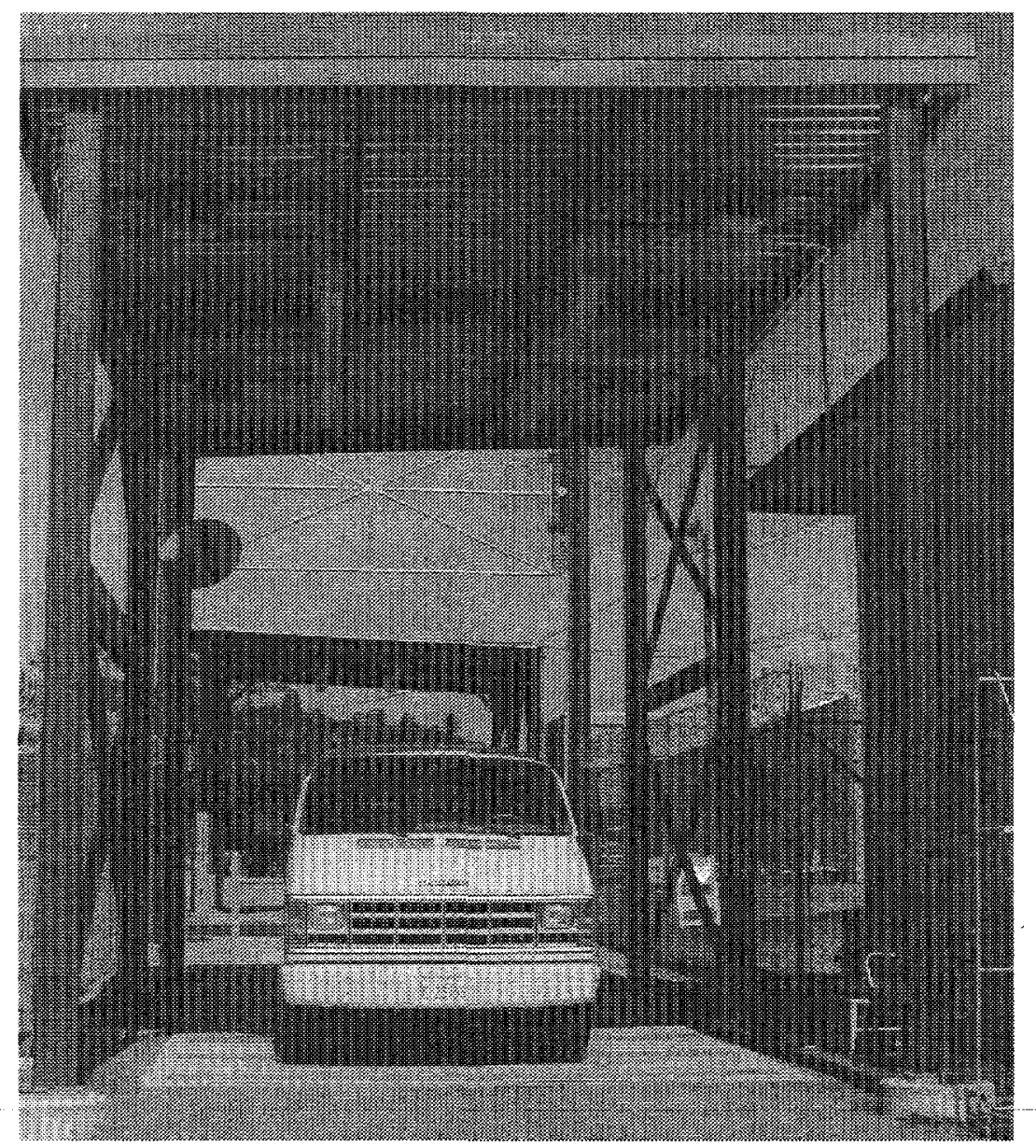

Fig. 5. A vehicle monitoring station at Los Alamos.

The monitoring station signal-conditioning electronics and microprocessor-based monitor control unit at Los Alamos are housed in a separate cabinet located near the detectors. The occupancy monitor in this case is a traffic-control magnetic loop that triggers the start of monitoring. When the vehicle monitoring station is first occupied, the monitor is preset for a short delay to allow the vehicle to come to a full halt. Then monitoring begins.

The moving-average method is not used for monitoring in the monitoring station because the vehicle is not moving, hence any signal is steady rather than varying in time. A single long measurement could be used, but another microprocessor method has the advantage that it will shorten the time required to achieve a given level of sensitivity. This technique is called the "sequential probability ratio technique," or SPRT,11 and is more fully described in Sec. III.D of Part II of this report. As does the moving average, the SPRT uses a sequence of short measurements for monitoring but it does so in a different manner.

11 A. Wald, "Sequential Analysis," Dover Publications, Inc., New York, 1973. 


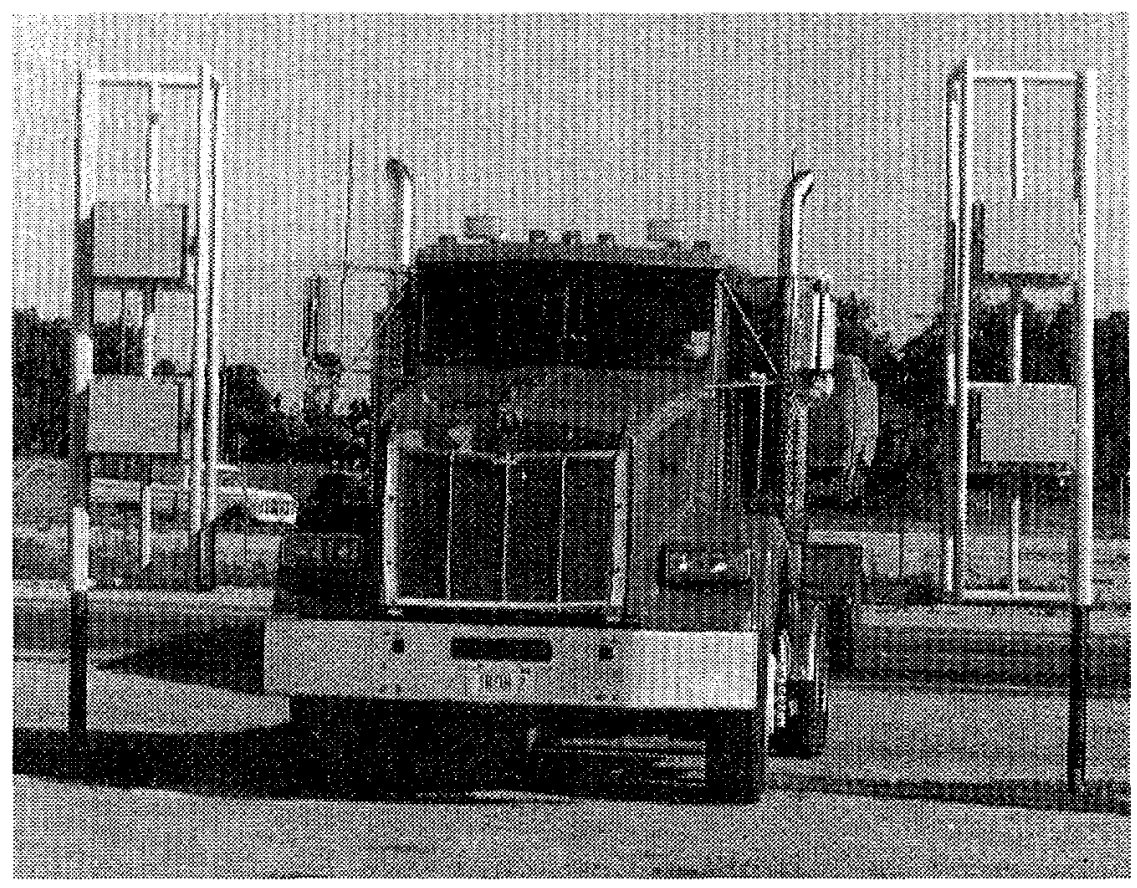

Fig. 6. A simple steel scrap monitor, the Ludlum Measurements, Inc., Model $3500^{12}$ gate monitor.

The principle of SPRT monitoring is to obtain a measurement result and then calculate the ratio of the probabilities that the result comes from two possible statistical distributions. One is a distribution of measurement results expected for background intensity and the other for a distribution expected for measurement results from background plus a radiation source. As measurement results are accumulated, an accumulated product of the ratios is compared with two thresholds, one a threshold for a decision of background and the other a threshold for a decision of background plus a source (alarm threshold). If the accumulated results are less than the background threshold or greater than the alarm threshold, a final decision can be made. If the accumulated results are greater than the background threshold but less than the alarm threshold, no decision can be made and another measurement begins as monitoring continues. If a decision can be made, the decision is announced and monitoring terminates. If a decision has not been made in a predetermined maximum allowed time, the procedure is truncated (stopped) and a background or alarm decision, whichever has been pre-selected, can be arbitrarily announced.

The advantage of the SPRT is that decisions usually can be quickly made when only background radiation intensity is present or when a strong source is present in addition to background. Hence, almost all routine traffic will be more quickly monitored, but with the same high detection probability as would be obtained in a much longer measurement. At Los Alamos, the average monitoring time is about one-third of that required for the same sensitivity with a single-measurement method.

12 Ludlum Measurements, Inc., PO Box 810, Sweetwater, TX 79556 (915-235-5494). 
The shortcoming of the SPRT lies in the possibility of not being able to make a decision after a practical number of measurements. In this case, monitoring can be truncated by stopping after a predetermined time and announcing an arbitrarily chosen decision of background or alarm.

Vehicle monitoring stations also use a remotely located information panel to inform security inspectors of alarms or lack of alarms during monitoring. Other information, such as suspension of monitoring during high- or low-background conditions can also be displayed and possibly audibly announced. An alarm-reset switch would also be located on the panel if alarms were not being automatically reset.

\section{Vehicle Monitoring Station Operation}

Vehicle monitoring stations are fully automatic monitors and require intervention by a security inspector only when long vehicles must be monitored. In that case, the security inspector sees to it that the truck is repositioned and then restarts the monitoring process.

Vehicle monitoring stations are located inside a vehicle trap at a protected area perimeter. While the vehicle monitoring station is unoccupied, background measurements are being made and alarm thresholds are being updated. When a vehicle is sensed, background measurement ends and a short delay elapses for the vehicle to be positioned; then monitoring begins.

An example of monitoring in vehicle monitoring station is the following. The microprocessor continuously makes simultaneous measurements of 4-s duration in each of four detectors groups and stores the results, whether or not a vehicle is present. Periodically, the results are used to establish a new average background and alarm threshold for each group. When a vehicle is sensed, monitoring begins, and as each measurement period is completed, the results for each group are recorded and used to calculate a probability ratio for each group. As new ratios are calculated, the running product of the ratios for each group is compared with the decision thresholds.

As monitoring proceeds, if an alarm decision can be made in any one detector group, then monitoring terminates with an alarm. If a background decision can be made in all groups, then monitoring can terminate with a background decision. Otherwise, measurements and monitoring must continue until a final decision can be made or the maximum monitoring time is reached.

When an alarm occurs in a vehicle monitoring station, it is best investigated by using a handheld monitor as described in the hand-held monitor user's guide (see reference 6). If no cause for an alarm can be located, the vehicle should be made to back out of the trap for more than two minutes while the monitor's background updates. Then the vehicle can re-enter for a second monitoring. If the monitor again alarms, then the question is whether the monitor is defective or whether the hand-held monitoring was not thorough enough. The safest resolution of the question would be obtained from information gained by both repeating the hand-held monitoring and then monitoring a different, but similar, vehicle. 


\section{Vehicle Monitoring Station Costs and Availability}

The cost of a vehicle monitoring station is divided between the architectural structure that houses the monitor and the components of the monitor itself. The structure provides both a means to house below-ground detector cabinets in trenches and a space frame to support overhead ones. The space frame also can be used to support a roof for weather protection to make hand-held monitoring more feasible, when needed.

The below-ground trenches should be well drained to prevent water build up, and all covers should be of aluminum plate to accommodate passage of gamma rays. The floor of the monitor should be well above grade, far enough to eliminate any chance of detector flooding, if at all possible.

The vehicle monitoring stations at Los Alamos were manufactured by Jomar Systems, Inc., ${ }^{13}$ now a part of Canberra Industries. TSA Systems, Ltd., has offered to supply a similar monitor, which would be their first attempt at this type of monitor.

Vehicle monitoring stations can make good use of two remote information modules. One is located inside the station to provide the necessary alarm sounder and indicator lamps. The second is located beside the monitor itself to inform an inspector stationed there of the monitor status. When the inspector sees the green indicator lamp, the exit gate can be opened. Another function of the outside module is to provide a restart switch for monitoring so that long vehicles can be monitored in sections.

Costs for vehicle monitoring stations could well be divided evenly between the monitor and the architectural structure. The 1987 estimate was about $\$ 75,000$ for each.

\section{Neutron-Detection-Based SNM Vehicle Portal Monitors}

\section{Description of a Neutron-Detection-Based Vehicle Portal}

The newest type of automatic vehicle SNM portal monitor uses large neutron-chamber detectors containing ${ }^{3} \mathrm{He}$ gas proportional counters for detecting neutrons from plutonium. These neutron-detection-based monitors have only recently become commercially available. The detector technology and alarm logic used for the monitors are adaptable to a variety of detector sizes and to applications ranging from pedestrian monitors to vehicle monitors. At the time of writing, our prototype monitor is operating at a DOE facility, and two similar-size monitors that were commercially produced are installed at another facility as emergency-exit monitors for pedestrians.

The neutron-detection-based monitors sense low-energy neutrons to detect plutonium, and they can do so even if the plutonium is shielded to hinder detection. The neutron-detection-based detector not only overcomes gamma-ray shielding by detecting neutrons, but it also overcomes neutron shielding. The detector does this by having a partially undermoderated design that benefits

13 Canberra Industries, Inc., Nuclear Products Group, 800 Research Parkway, Meriden, CT 06450 (203-639-2481). 
from the presence of any additional moderating materials such as neutron shielding. Neutron shielding materials, within practical limits, can increase an undermoderated detector's response. ${ }^{14}$

The neutron vehicle portal detectors are two large polyethylene-lined boxes that form the portal that a vehicle must pass through while being monitored. The polyethylene liner of each detector box is thin in the direction of a vehicle and thick in the opposite direction. The thin liner allows both low- and high-energy neutrons to enter and the thick back wall provides moderation for the fast neutrons. Low-energy neutrons from collisions in either wall follow random paths and can find themselves trapped in the hollow space for a while. Four neutron proportional counters are located in the hollow area of each detector box to detect trapped low-energy neutrons.

The monitor's signal-conditioning electronics and microprocessor-based control unit are likely to be housed in a separate cabinet. A remote information panel would be located in an entry-control station to inform security inspectors of alarms and to provide an alarm-reset switch, if required. An occupancy monitor, such as a passive infrared detector or a traffic-control magnetic loop, may be used to trigger the start of monitoring. When the vehicle portal is occupied, monitoring is continuous until an alarm occurs or the occupancy sensor returns to its unoccupied state.

\section{Neutron-Detection-Based Vehicle Portal Operation}

Neutron-detection-based vehicle portal monitors also are fully automatic monitors that require little intervention by a security inspector. They are located where vehicles are slowing to a stop for clearance to enter or exit a protected area, usually in a vehicle trap at an entry station.

While the vehicle portal monitor is unoccupied, background measurements are being made and alarm thresholds are constantly updated. Whenever a vehicle is sensed, monitoring begins. Because neutron count rates are very low, a special neutron controller is used by the monitor. The controller uses a low-count-rate SPRT method, called the Poisson sequential probability ratio test. The basic count interval of $0.6 \mathrm{~s}$ and nominal passage time of $3 \mathrm{~s}$ are much like the conventional vehicle SNM portal monitors, as might be expected since both monitor moving vehicles. However, the background count is derived from longer measurements $(\sim 120 \mathrm{~s})$ because of the low neutron background count rate.

As with the moving-average method, the Poisson SPRT makes a series of single-interval measurements to achieve higher sensitivity by capturing the highest possible measurement result. When alarms occur in this type of vehicle portal, they are investigated using a hand-held monitor having a plastic scintillator, which is gamma-ray and neutron sensitive, to search for the cause. A thorough search, as described in the hand-held monitor user's guide (see Ref. 6), may disclose the cause, or, if not, the vehicle can be made to back out of the trap long enough for the background to update, and then re-enter to be monitored once more. If the automatic monitor alarms again, then the question is whether the hand-held monitoring was not thorough enough. This calls for repeating the hand-held monitoring and, if no cause is discovered, then driving a different but similar vehicle through the automatic monitor to be sure that the monitor itself is not defective.

14 Paul E. Fehlau, "Integrated Neutron/Gamma-Ray Portal Monitors for Nuclear Safeguards," IEEE Trans. Nucl. Sci., Vol. 4, No. 4, pp. 922-926, August 1994. 


\section{Neutron-Detection-Based Vehicle Portal Cost and Availability}

The cost of neutron-detection-based vehicle monitors are expected to be in the neighborhood of $\$ 70,000$, although costs may decrease in the future. Neutron-detection-based vehicle SNM portal monitors are listed in one manufacturer's catalog (Canberra Industries, Inc. ${ }^{13}$ ).

Canberra's monitor is described in Part III of this report in Sec. II.B.3.

\section{PART II \\ TECHNICAL INGREDIENTS OF VEHICLE SNM MONITORING}

In this part, you will find a more technical, but still brief, review of some of the basic technology that has an important impact on the performance of vehicle SNM monitors.

\section{FACTORS THAT AFFECT VEHICLE SNM MONITOR PERFORMANCE}

\section{A. General Influences on SNM Monitor Performance}

\section{SNM Factors}

The radiation characteristics of SNM are essential to detecting them in SNM monitors. These characteristics are reviewed in a report of the early work at Los Alamos on SNM portal monitoring. ${ }^{15} \mathrm{~A}$ table from that report is reproduced below in Table I. The isotope $235 \mathrm{U}$ gives weapons-grade uranium its gamma-radiation characteristics, the isotope 239Pu does the same for weapons-grade plutonium, and ${ }^{238} \mathrm{U}$ is the major isotope found in depleted uranium. The important features to notice are that the activity of the plutonium is much greater than that of enriched uranium, the number of penetrating gamma rays emitted is much larger for plutonium, and the energy range of the emitted radiation is much greater for plutonium. As a result, plutonium is much more readily detected in a vehicle monitor because its radiation is both more penetrating and more intense. On the other hand, depleted uranium is relatively hard to detect in comparison to both plutonium and enriched uranium because it emits very little radiation at all.

One compensating factor for the lower radiation energy and intensity for uranium, as far as material accountability and physical protection are concerned, is that uranium is a less efficient fissionable material and is therefore less attractive. Accountability rules use a weighting factor for significance of uranium that is only $40 \%$ of that for plutonium. For example, $5 \mathrm{~kg}$ of highly enriched uranium is considered equivalent to $2 \mathrm{~kg}$ of plutonium as far as physical protection is concerned. Hence, uranium usually needs to be detected only in relatively larger quantities than plutonium.

Besides the inherent activity of SNM, its physical form has an important impact on its being detected in a vehicle portal monitor. The reason is that all forms of SNM are very dense materials

15 W. H. Chambers, H. F. Atwater, P. E. Fehlau, R. D. Hastings, C. N. Henry, W. E. Kunz, T. E. Sampson, T. H. Whittlesey, and G. M. Worth, "Portal Monitor for Diversion Safeguards," Los Alamos Scientific Laboratory report LA-5681 (December 1974). 
that easily absorb their own gamma-ray emissions. Hence, most of the radiation that reaches a monitor's detectors comes from the surface of the SNM. If the SNM is in fine granular form, it has a large surface area and produces a large signal. More compact forms, such as metallic shapes, absorb much of the emitted radiation and less is available to reach a detector. This is illustrated in Fig. 25 of Ref. 15.

\section{Passage Speed}

A complementary factor to the radiation intensity of the SNM source is the duration or time history of that radiation intensity near the monitor's detectors. The time histories are quite different in the two types of SNM monitor, the drive-through portals and wait-in monitoring stations. The stationary SNM in a vehicle parked in a vehicle monitoring station provides a constant signal that is available for measurement as long as is needed. However, in the drive-through portal monitors, the source intensity varies appreciably during passage, rising during approach and diminishing thereafter, and it must be measured during the short time that it is present.

Figure 7 is an illustration of the variable intensity profile in a vehicle portal, published in an earlier report ${ }^{16}$ on vehicle monitoring. The figure shows how the monitor's count rate varies when a vehicle with and without an SNM source is positioned at different points along the path, followed by vehicles moving through the portal. The data would correspond to a speed of about $8 \mathrm{~km} / \mathrm{h}$ ( $5 \mathrm{mph}$ ) if five intervals were used to form a 2 -s moving average. Note that without SNM, the vehicle reduces the monitor's count rate.

Table I. Gamma-ray activity of SNM in selected energy regions.

\begin{tabular}{|c|c|c|c|c|}
\hline \multirow[b]{2}{*}{ Isotope } & \multirow[b]{2}{*}{$\begin{array}{c}\text { Decay Rate } \\
\text { (dps/g) }\end{array}$} & \multicolumn{2}{|c|}{ Gamma Activity } & \multirow[b]{2}{*}{ Comments } \\
\hline & & $\begin{array}{c}\text { Energy Range } \\
(\mathrm{keV})\end{array}$ & $\gamma / \mathbf{s}-\mathbf{g}$ & \\
\hline $235 \mathrm{U}$ & $7.997 \times 10^{4}$ & $75-210$ & $6.18 \times 10^{4}$ & $\begin{array}{l}\text { Does not include geometry-dependent } \\
\text { uranium K x-rays in } 100 \text {-keV region, } \\
\text { which approximately double the listed } \\
\text { intensity if included. }\end{array}$ \\
\hline${ }^{239} \mathrm{Pu}$ & $2.268 \times 10^{9}$ & $\begin{array}{r}80-770 \\
197-451\end{array}$ & $\begin{array}{l}3.33 \times 10^{5} \\
1.34 \times 10^{5}\end{array}$ & $\begin{array}{l}\text { Does not include geometry-dependent } \\
\text { plutonium } \mathrm{K} \mathrm{x} \text {-rays in } 100-\mathrm{keV} \text { region } \\
\text { and age-dependent }{ }^{241} \mathrm{Am} \text { from }{ }^{241} \mathrm{Pu} \\
\text { decay, which can dominate the } \\
\text { spectrum and overwhelm the listed } \\
\text { intensities. }\end{array}$ \\
\hline $238 \mathrm{U}$ & $1.244 \times 10^{4}$ & $\begin{array}{r}80-1001 \\
700-1001\end{array}$ & $\begin{array}{l}129 \\
121\end{array}$ & $\begin{array}{l}\text { Strong bremsstahlung below } 500 \mathrm{keV} \\
\text { from } \beta^{-} \text {of }{ }^{234} \mathrm{Th} \text { and geometry- } \\
\text { dependent uranium } \mathrm{K} \text { x-rays in } 100-\mathrm{keV} \\
\text { region not included. }\end{array}$ \\
\hline
\end{tabular}

16 P. E. Fehlau, C. Garcia, Jr., R. A. Payne, and E. R. Shunk, "Vehicle Monitors for Domestic Perimeter Safeguards," Los Alamos National Laboratory report LA-9633-MS (1983). 


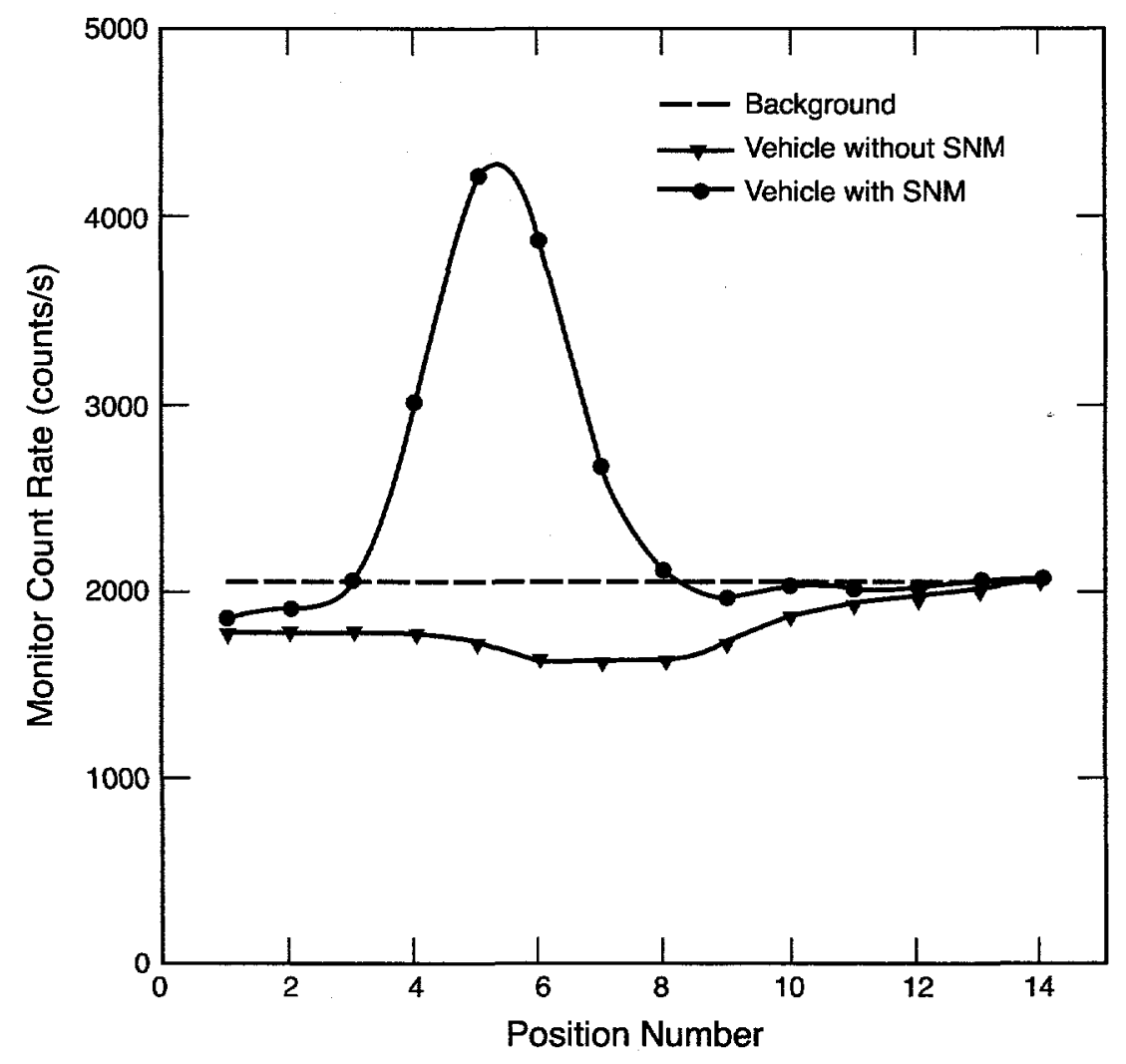

Fig. 7. Monitor count rates as a vehicle is moved through a portal. Without a source, the vehicle reduces the monitor's count rate below background, whereas with SNM there is a net increase that reflects passage of a radiation source.

\section{B. Particular Influences on Performance: Pedestrian/Vehicle Monitor Differences}

The hardware and detectors used in pedestrian SNM monitors and vehicle SNM monitors are very similar, and in some cases, the hardware used is identical. However, there are important differences between the two types of monitor that affect monitoring performance.

\section{Background Reduction During Occupancy}

Pedestrian monitors are not significantly affected by their occupant. The monitor's background count rate may be slightly reduced by the presence of a pedestrian (who absorbs some of the background radiation), but the amount is usually negligible, less than $1 \%$ of the background count rate and much less than the increment used to establish the alarm threshold (5\% or so of the background count rate). The amount of background reduction can change if the portal width is changed to move the detectors closer, which increases background reduction, or farther away from pedestrians, which decreases background count rate reduction. However, the amount of the reduction is always small in pedestrian portals, and the portal spacing is usually made as narrow as possible to obtain the greatest sensitivity to radiation from SNM.

Vehicle portal monitors are much more affected by occupying vehicles, and the background count rate reduction during occupancy is much larger (see Fig. 7). The earlier vehicle monitor 
applications guide (see Ref. 3) indicates that measured background count rate reductions by vehicles commonly encountered at Los Alamos range from $6 \%$ to $27 \%$, all of which are greater than the increment used for the alarm threshold. The greater reduction in background count rate results from vehicles being much more effective absorbers of background radiation because of their great size and metallic construction. As a result, vehicle monitoring requires a relatively greater SNM source intensity for detection than just enough to exceed the alarm threshold (background plus alarm increment) as would be required in a pedestrian monitor or an empty vehicle monitor. To exceed the alarm threshold of an occupied vehicle monitor, an SNM source must raise the occupied monitor's background count rate enough to overcome both the background count rate reduction caused by occupancy and the alarm increment, instead of just the alarm increment.

The extent of background count rate reduction by a vehicle occupying a vehicle portal monitor can be changed. Decreasing the spacing between detectors to improve detection of radiation from SNM will also increase the amount of background count rate reduction; the net effect may well be an overall decrease in sensitivity. Increasing the spacing between the detectors can reduce the amount of background count rate reduction but also reduces the response of the detectors to sources contained in the vehicle; this also can lead to an overall decrease in sensitivity. The happy medium at Los Alamos that offered the best overall response was a region around a spacing of $5.2 \mathrm{~m}(17 \mathrm{ft})$, where small increases or decreases in spacing had little effect on sensitivity. This spacing has been used unless another spacing is required for practical reasons such as for an existing gate width or to accommodate the turning radius for large vehicles.

\section{Source Attenuation by Vehicles}

Not only do vehicles reduce a monitor's background count rate, they also can absorb some of the radiation emitted by any SNM radiation sources that are located inside of them. Both the structural materials of the vehicle and the contents of the vehicle are capable of attenuating SNM source radiation. The original vehicle monitor applications guide (see Ref. 3) gives information on the maximum SNM source attenuation in various vehicles. The amount of attenuation ranges from about $40 \%$ to $80 \%$ of the total radiation that would be detected if the vehicle were not there. The corresponding attenuation effects in pedestrian monitors is much less because only bone, flesh, and clothing should be present as radiation attenuators, and any SNM would be located on a body surface that will be exposed to the detectors at some time during passage.

\section{Source Passage Speed}

Passage speed is another factor that affects performance. Greater speed makes faster monitoring necessary, which leads to using shorter monitoring measurements that are less precise and reduce sensitivity. The speed of pedestrians is relatively easy to control, and the possible variation in their speed can be kept small by observing their passage to prevent unusual behavior. Vehicles, on the other hand, are capable of a broad range of speed, and the speed of a vehicle is harder for an observer to judge. Hence, vehicle portals are best located at a point where vehicles must stop and await clearance to pass through an entry gate to a vehicle trap. Then the vehicle passes through the monitor from a standing start and doesn't build up much speed because it must stop in the trap after traveling only a short distance. 


\section{EFFECTIVE SNM-MONITOR DETECTORS}

\section{A. Plastic Scintillators}

Solid organic radiation detectors are solutions of fluorescent organic compounds in a polystyrene or polyvinyltoluene matrix that can produce a practical level of light output for radiation detection. ${ }^{17}$ These are commonly called "plastic" scintillators because that term is routinely used for commercial products manufactured from solid organic materials. As with other scintillators, radiation absorbed by the material leads to excitation of the fluorescent compounds, which then decay by emitting flashes of light. Scintillation light from the plastic scintillator is sensed with an attached photomultiplier that converts the light into pulses of electrical current. Figure 8 illustrates their use.

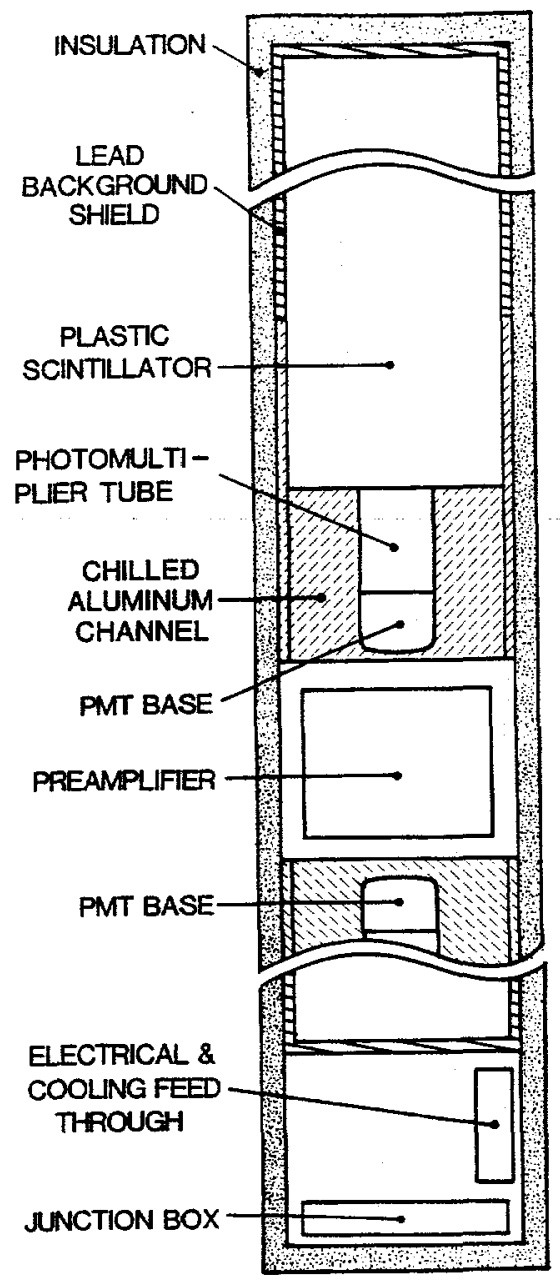

Fig. 8. Two plastic scintillators are diagrammed in this vehicle SNM portal monitor cabinet designed for use in a desert region. Insulation and thermoelectric cooling were used to control the cabinet temperature.

17 C. R. Hurlbut, "Plastic Scintillators, A Survey," a paper presented at the November 1985 meeting of the American Nuclear Society. Available from the Bicron Corporation, 12345 Kinsman Road, Newbury, OH 44065 (216-564-2251). 
Plastic scintillators are large, inexpensive detectors with good spatial uniformity and good high-energy gamma-ray response. They are available in almost any size and shape, and the large size used in SNM monitors allows them to intercept great amounts of radiation (large solid angle). The ability of plastic scintillators to convert radiation to light, which is called the intrinsic detection efficiency of a scintillator, is actually less in plastics than in inorganic scintillators such as thalliumactivated sodium iodide ( $\mathrm{NaI}(\mathrm{Tl})$ ), but that shortcoming is easily made up by using larger detectors with an increased solid angle for intercepting the radiation. So, with a much larger total detector size, plastic scintillation detectors can have as large or larger total efficiency for detecting SNM radiation and equal or exceed the performance of other detectors at the same cost.

Aspects of designing a plastic scintillation detector that are important for vehicle SNM monitoring include attaching a light pipe between the scintillator and photomultiplier to improve the scintillator's uniformity of response to radiation, using scintillator material with a polished surface for obtaining good light transmission over the scintillator length, and then wrapping the scintillator with aluminum foil before applying a light-tight outer covering. The aluminum foil preserves an air interface at the scintillator's surface that is necessary for total internal reflection of light transmitted along the scintillator's length. Placing tape directly on the scintillator would destroy that interface and lead to loss of light instead of reflection.

The non-scintillating light pipe is bonded to the plastic scintillator and provides a dead region near the photomultiplier where the solid angle for light collection is extremely high. The dead region removes an over-response to scintillations near the photomultiplier and both reduces the background count rate and makes light collection from the entire scintillator much more uniform.

Raw materials for making plastic scintillation detectors are available in addition to finished scintillators. Instructions for do-it-yourself detectors are available. ${ }^{18}$

\section{B. Neutron Chamber Detectors}

Neutron chamber detectors are another example of an inexpensive, large, relatively low efficiency detector that benefits from its ability to intercept large amounts of radiation. These detectors are composed of a hollow polyethylene box for moderating fission neutrons and one or more neutron proportional counters for detecting the moderated neutrons.

${ }^{3}$ He neutron proportional counters are most often used; they detect thermal neutrons when a ${ }^{3} \mathrm{He}$ nucleus captures a neutron, making an unstable nucleus that fragments into two charged particles, a proton and a triton. The proton and triton (a nucleus comprising a proton and two neutrons) both produce ionization in the proportional counter that can be collected to produce countable electrical current pulses.

Fast neutrons from plutonium must first be slowed to near-thermal energies before they can be detected with reasonable efficiency. The means for slowing neutrons is called a moderator. This is simply a material containing lots of hydrogen that can scatter incident neutrons and reduce their energy. Plastics, such as polyethylene, are hydrogen rich and are very efficient at moderating

18 P. E. Fehlau and G. S. Brunson, "Coping with Plastic Scintillators in Nuclear Safeguards," IEEE Trans. Nucl. Sci. NS- $\underline{30}, 158$ (1983). 
neutrons. Once neutrons are moderated, they are available for capture, either by hydrogen in the moderator or by ${ }^{3} \mathrm{He}$ in a proportional counter.

The straightforward approach to making a neutron detector would be to bury as many ${ }^{3} \mathrm{He}$ proportional counters as possible in polyethylene, using a thickness of about $5 \mathrm{~cm}$ ( 2 inches) of polyethylene on each side of a row of proportional counters. However, this becomes very expensive when making a detector large enough to intercept a reasonable number of neutrons. The major expense is in the large number of proportional counters.

A more reasonable approach is to make the moderator large, but then leave it hollow and position a few proportional counters in the hollow space. Then, once neutrons are moderated in the polyethylene, those that enter the hollow space can bounce around a bit and possibly reach one the proportional counters and be detected. If the moderator were not hollow, then moderated neutrons would be much more likely to be captured by hydrogen instead of by ${ }^{3} \mathrm{He}$ in a proportional counter. Figure 9 illustrates the components of a neutron chamber detector.

Another aspect to the hollow moderator is that the moderator walls need not be uniformly thick. The back and side walls can be made thick enough to moderate fast neutrons and return them to the hollow chamber. The entry wall, the one nearest the vehicle being monitored, can be made thin, so that both fast and slow neutrons can enter the detector. This aspect of the neutron chamber detector allows it to have a broad response to neutrons that allows it to detect neutrons from both bare plutonium and from plutonium that may be contained inside of a moderating object or shield. Figure 10 reproduces data from a recent publication ${ }^{19}$ that illustrates that a monitor's response can be made to increase when moderator is added around the plutonium.

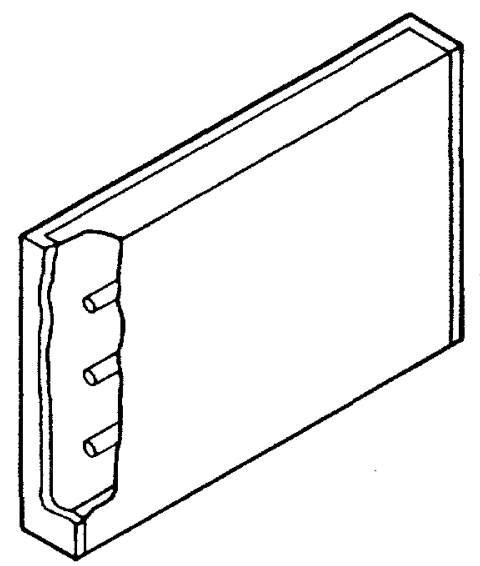

Fig. 9. A neutron chamber detector.

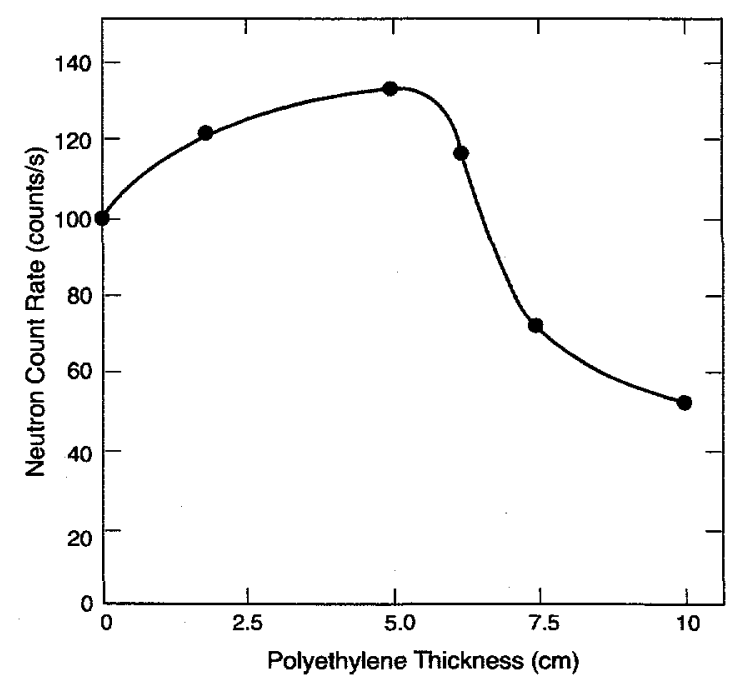

Fig. 10. A neutron chamber detector response to increasing thickness of polyethylene moderator placed around a source.

19 Paul E. Fehlau, "Integrated Neutron/Gamma-Ray Portal Monitors for Nuclear Safeguards," IEEE Trans. Nucl. Sci., Vol.4, No. 4, pp. 922-926, August 1994. 


\section{EFFECTIVE METHODS FOR MAKING MONITORING DECISIONS}

Many methods are available for making monitoring decisions. All of them establish an alarm threshold for comparison with monitoring results in making monitoring decisions. After that, monitoring methods use either a single measurement and decision or they perform multiple measurements and make a series of monitoring decisions. This section discusses alarm thresholds and then compares the single interval method with the multiple measurement methods, moving average and sequential probability ratio test, that are later discussed in detail.

\section{A. Alarm Thresholds}

Radiation monitors must operate in an environment that has some amount of background radiation from the natural environment and other possible sources. In the best of circumstances, the background radiation intensity is relatively constant.

The signature radiation from SNM that is detected by a monitor must produce a significant change in the monitor's total measured radiation intensity if it is to be detected. The change in intensity would be a step increase for a wait-in monitor, such as a vehicle monitoring station. However, in a portal monitor the SNM is in motion during monitoring and gives a varying change in intensity. The important difference here is that in one case a constant intensity is measured and in the other a varying intensity.

The first task a monitor must perform is to maintain timely information on its background count rate. Monitors do this by continually measuring the number of counts accumulated in a modest interval of time ranging from tens of seconds to a few minutes, depending on the application. The resultant count can then be converted to an new average background for the monitor by dividing by the measurement time, which gives the background in counts per second. This result is appropriate for displaying the monitor's count rate in recognizable terms, but it may have to be further converted for use by the monitor's decision logic. The background used by the detection logic would be the number of counts expected in the time interval used by the detection logic, for example, a counts/s result multiplied by the time interval used in monitoring.

The second task a monitor must perform is to maintain a timely alarm threshold for the monitor. The alarm threshold will be greater than the average count per monitoring interval by an amount, called an alarm increment, that will make it relatively unlikely to be exceeded by the normal statistical variation in the monitoring measurement results when only background radiation is present. If the standard deviation of a monitoring measurement is known, some multiple of it can be added to the average background to obtain an alarm threshold. The chosen size of the multiple will depend on both the likelihood of a single measurement exceeding the average and the estimated number of decisions that will be made during monitoring.

As an example of setting an alarm threshold, consider the following. The monitor background is B counts per monitoring interval, and the counting measurement results are numerically large enough that their statistical distribution can be approximated by a normal distribution, so the standard deviation is estimated by the square root of the background (B). Using an alarm threshold A equal to $\mathrm{B}+4 \mathrm{xB}^{0.5}$ during monitoring, the probability of exceeding the threshold will be $3.16 \mathrm{x}$ 
$10^{-5}$ for each comparison of a measurement with the alarm threshold if the background is exactly determined. When the threshold is exceeded in this case, such alarms (ones not caused by SNM but by statistical variation) are often referred to as nuisance alarms. If only one comparison is made during monitoring, this is the final result: about 1 nuisance alarm from statistical variation per 30,000 passages (if background is exact). However, if an average of 10 such comparisons are made during passage in a vehicle portal, one would then expect a nuisance alarm rate from statistical variation of about $3 \times 10^{-4}$, or about 1 in 3000 passages (with exact background). Note that backgrounds are never exactly determined and the statistical error in background measurements carries over into the alarm threshold and consequent nuisance alarm rate making them somewhat higher than described here.

At lower count rates, as in neutron-detection-based monitors, the normal approximation used above does not apply. An alarm threshold should be calculated from first principles whenever needed, but a more practical approach has been taken in one case by simply calculating a look-up table of alarm thresholds for various backgrounds and including it in the monitor's firmware.

\section{B. A Comparison of Single- and Multiple-Measurement Methods}

The single interval method is not often used in monitoring, but it serves as an illustration of why other methods are used.

In the single interval method, one and only one monitoring measurement is made. Once the result is available, it is compared with the alarm threshold, and then the appropriate action, red (alarm) or green (no alarm) indications are given, and the vehicle is allowed to proceed or is further searched, as appropriate.

The shortcoming of the single interval method for vehicle portals is that the vehicle is in motion and will not necessarily be in the right position to measure the largest possible SNM signal during a single measurement period. Figure 7 in Sec. I.A of this part illustrated how the signal from a vehicle varies as it passes through a vehicle portal monitor.

The situation can be improved by using a moving average approach in which shorter measurements are made continuously for as long as the vehicle is present. A number of measurement results are averaged together, with the oldest discarded as new results are obtained, to make a moving-average measurement result for comparison with the alarm threshold. This makes it possible to measure the largest practical SNM signal without having to coordinate the start of monitoring with the location of the SNM. But, note that the method uses more measurement comparisons, so the alarm threshold must be increased to obtain the same nuisance alarm rate as with the single interval test. However, even though the alarm threshold is greater, the increase in signal is large enough that the moving average gives greater sensitivity.

There is also a shortcoming for the single-interval method in vehicle monitoring stations because the entire monitoring time, which may be minutes long, must be used for each vehicle, even those not transporting SNM or transporting large amounts of SNM. The solution here is to use the sequential probability ratio test, a procedure that makes a series of short measurements and, at each step, calculates the ratio of the probabilities that the results stem from a background count 
distribution or a background plus SNM-signal distribution. The ratio is compared with two decision thresholds, one for a background decision and one for an alarm decision. If a decision can be made, it will be made; otherwise another measurement is made, another probability ratio is calculated, and a running probability ratio is compared to the two thresholds, and so forth.

One of the strong points of the sequential probability ratio method is that it usually makes rapid decisions for below background or well-above-background radiation intensities. Hence most vehicles, which attenuate some of the background radiation and lower the monitor's count rate, will require very little monitoring time. Similarly, vehicles transporting strong sources of radiation will also be quickly monitored. Only borderline cases will use the maximum allowed monitoring time. As a result, this procedure allows most vehicles to be monitored as thoroughly as with other methods but allows most of them to proceed in a far shorter time.

\section{The Moving-Average Method}

An example of the moving-average method used for a vehicle SNM portal monitor has a moving-average value $\left(\mathrm{MA}_{\mathfrak{i}}\right)$ that is the sum of the four most recent 0.5 -s measurement results $\left(\mathrm{N}_{\mathrm{i}}\right.$ ), that is it operates with 2-s average values that are updated after each new 0.5 -s measurement. The first average after occupancy is arrived at by summing the three most recent measurement values that had been stored during the vehicle's approach and the first measurement value stored after occupancy was sensed. When each successive new measurement result is available, it is stored and then summed with the three most recent previously stored results. For example,

$$
\mathrm{MA}_{\mathrm{k}}=\mathrm{N}_{\mathrm{k}}+\mathrm{N}_{\mathrm{k}-1}+\mathrm{N}_{\mathrm{k}-2}+\mathrm{N}_{\mathrm{k}-3}
$$

would be the first monitored moving average if the first stored monitoring result is $\mathrm{N}_{\mathrm{k}}$.

The alarm threshold for this example of the moving average method uses four times the 0.5 -s average background measurement value $\left(\mathrm{N}_{\text {av }}\right)$ as its average and a multiplier of 4 times the square root of that average as its estimate of the standard deviation:

$$
\mathrm{ALM}=4 \mathrm{~N}_{\mathrm{av}}+4\left(4 \mathrm{~N}_{\mathrm{av}}\right)^{0.5}
$$

During monitoring, each new $\mathrm{MA}_{\mathrm{i}}$ is compared with the alarm threshold (ALM). An alarm results if the threshold is equaled or exceeded:

$$
\mathrm{MA}_{\mathrm{i}}>=\mathrm{ALM} \text {. }
$$

The duration of the moving average used here, $2 \mathrm{~s}$, is representative of the duration of the signal from an SNM-carrying vehicle traveling at $8 \mathrm{~km} / \mathrm{h}$ passing midway between detectors spaced about $5.2 \mathrm{~m}$ apart. Other speeds and spacings may benefit from different averaging times. The number of subintervals being used in vehicle portals, four or five, stems from an analysis of the optimum number of subintervals reported ${ }^{20}$ for pedestrian monitors. The other measured

20 W. H. Chambers, H. F. Atwater, P. E. Fehlau, R. D. Hastings, C. N. Henry, W. E. Kunz, T. E. Sampson, T. H. Whittlesey, and G. M. Worth, "Portal Monitor for Diversion Safeguards," Los Alamos Scientific Laboratory report LA-5681 (December 1974). 
parameter, the average background, in this case could be calculated from 50 of the $0.5-\mathrm{s}$ measurement intervals whenever the monitor is unoccupied, allowing an average background update every $25 \mathrm{~s}$.

\section{The Sequential-Probability-Ratio Test Method}

The SPRT method for vehicle monitoring stations tests the hypothesis that a sequence of measurement results is from a background count distribution against the hypothesis that it is from an alarm count distribution arising from background plus a radiation source. The SPRT has two decision thresholds, one for each outcome, background or alarm. If neither decision can be made, additional measurements are included in sequence until a decision can be made. To avoid excessively long sequences, the SPRT is truncated at some point, for example at about a minute for a vehicle monitoring station, and one of the decisions is then imposed, either background or alarm depending on the monitoring-sensitivity and nuisance-alarm goals for particular situations.

The quantity tested in the SPRT is the ratio of the normally distributed probabilities that each measurement is from the background distribution with average $\mathrm{N}_{\mathrm{av}}$ or from the alarm distribution with average $\mathrm{N} 1$. The probability ratio for a sequence of measurements is the product of the probability ratios for the individual measurements in the sequence. For simplicity, the natural logarithm of the probability ratio is used for the tested quantity, and the successive terms can be added instead of multiplied. In the following, we use $\mathrm{Z}$ to designate the logarithm of a probability ratio. A further simplification uses $\mathrm{N}_{\mathrm{av}}$ to estimate the variance of both distributions, which are nearly the same in high sensitivity monitors. Using this approximation, the form of the logarithmic terms in a sequence of probability ratios is given by the following equation:

$$
\mathrm{Z}_{\mathrm{i}}=\left[0.5\left(\mathrm{~N}_{\mathrm{i}}-\mathrm{N}_{\mathrm{av}}\right)^{2} / \mathrm{N}_{\mathrm{av}}\right]-\left[0.5\left(\mathrm{~N}_{\mathrm{i}}-\mathrm{N} 1\right)^{2} / \mathrm{N}_{\mathrm{av}}\right] \text {, }
$$

where each of the various Ns is in units of counts per single measurement interval.

$\mathrm{N}_{\mathrm{av}}$ is a measured value, but the value used for $\mathrm{N} 1$ is somewhat arbitrary and can be precisely determined for specific cases to achieve a desired sensitivity and nuisance alarm rate. In our most recent control units, we use look-up tables of precisely determined values, and the computer simulations for doing this are described in two references..$^{21,22}$ Earlier, we used an approximation for variable count rates from a conference report ${ }^{23}$ that gives an estimate of how large $\mathrm{N} 1 \mathrm{might}$ be in familiar terms. In this example, the approximation for the mean of an alarm distribution uses an increment above background proportional to that which would be used in a nominal fourmeasurement moving-average method that has a 4 standard deviation alarm threshold. ${ }^{24}$

$$
\mathrm{N} 1=\mathrm{N}_{\mathrm{av}}+2\left(\mathrm{~N}_{\mathrm{av}}\right)^{0.5}
$$

21 Kenneth L. Coop, "Monte Carlo Simulation of the Sequential Probability Ratio Test for Radiation Monitoring," IEEE Transactions on Nuclear Science, Vol. NS-32, No. 1, February 1985.

22 Kenneth L. Coop, "Computer Simulation of the Sequential Probability Ratio Test for Nuclear Safeguards," Los Alamos National Laboratory report LA-10499-MS, July 1985.

23 P. E. Fehlau, J. C. Pratt, J. T. Markin, T. Scurry, Jr., "Smarter Radiation Monitors for Safeguards and Security," Nuclear Materials Management XII (Proceedings Issue), 122 (1983). used to multiply $\mathrm{N}_{\mathrm{av}}$. The result here is simply $2\left(\mathrm{~N}_{\mathrm{av}}\right) 0.5$. 
Keep in mind that, for the SPRT, this equation gives the average N1 used for the alarm count distribution rather than an alarm threshold, which appears similar in the moving-average method.

At each step in an SPRT sequence, the sum of the $\mathrm{Z}$ terms is compared with the background threshold (ALB) and also is compared with the alarm threshold (ALA). These parameters are also arbitrary and can be adjusted to achieve particular sensitivity and nuisance alarm goals in specific monitors. The background threshold in one particular monitoring example is

$$
\mathrm{ALB}=-0.693,
$$

and the alarm threshold is

$$
\mathrm{ALA}=8.3
$$

To illustrate use of the thresholds, a background decision for a measurement designated $\mathrm{k}$ coming after three steps in a sequence would result from the condition

$$
\mathrm{Z}_{\mathrm{k}-2}+\mathrm{Z}_{\mathrm{k}-1}+\mathrm{Z}_{\mathrm{k}}<\mathrm{ALB}
$$

and similarly an alarm decision after two steps would result from the condition:

$$
\mathrm{Z}_{\mathrm{k}-1}+\mathrm{Z}_{\mathrm{k}}>\mathrm{ALA}
$$

If neither condition is met, another measurement is made, $\mathrm{Z}_{\mathrm{k}+1}$ is calculated and added to the sequence, and the result is once more compared with the two thresholds.

As used in vehicle monitoring stations, the individual SPRT measurements might be $4 \mathrm{~s}$ long. Backgrounds could be determined from an average of 30 individual 4-s measurements, and the background could be completely updated at 2-min intervals, when the monitor is unoccupied. During monitoring, a single decision would be made using as many measurements as needed, up to a limit of perhaps $15(1 \mathrm{~min})$. If the limit is reached, monitoring would cease and a decision would be arbitrarily imposed. A background decision would be a safe choice in cases where the monitoring station is used together with other security measures as the outer layer of protection. In other circumstances, where the highest possible sensitivity is needed, the alarm condition may be a better choice.

As a practical matter, the background update process for a monitoring station would likely use a moving average rather than a single measurement because two minutes of unoccupied time at a busy station might take quite a while to accumulate. The moving average would allow partially updating the background more frequently and perhaps avoid problems caused by variable background intensities.

The SPRT also may be used in vehicle portal monitors. The reason is that it can be operated in a continuous mode in which another monitoring sequence begins whenever a background decision or truncation point is reached. In this case, monitoring can begin as a vehicle approaches, and then, using a series of SPRT sequences, the vehicle will continuously be monitored as it passes through the portal, much like the procedure using the moving-average method. The SPRT needs few 
measurements for background decisions in a vehicle portal because vehicles partially shield the detectors from background. However, if a small signal is present, the SPRT needs more measurements to make a decision and effectively concentrates the signal so that sensitivity is enhanced, just as in the moving-average method. If there is no alarm, the SPRT continues until the vehicle departs.

For vehicle portal monitoring, 0.4-s measurements can still be used but with a shorter maximum sequence length of perhaps 5 . The method can be made equal to the moving average in both sensitivity and nuisance alarm rate, as evidenced by a recent study of such equivalence in pedestrian monitors. ${ }^{25}$

\section{OPERATOR TRAINING}

Operator training is essential to allow security inspectors to become familiar with radiation, SNM, the elements of automatic monitoring, and the method for carrying out searches with a handheld SNM monitor. The early sections of this report provide an example of an introduction to radiation and SNM monitoring (see Secs. I - III of Part I). The hand-held SNM monitor user's manual (see Ref. 6) describes hand-held monitor search techniques for pedestrians and vehicles.

Training in the use of hand-held monitors should include both an introduction to the types of monitor that will be used and an introduction to the technique for searching with it. Hands-on practice with the hand-held monitors is also essential. Practice can involve searching for small isotopic check sources such as $1 \mu \mathrm{Ci}$ of ${ }^{133} \mathrm{Ba}$ ( 1 microCurie of barium-133), that can be easily hidden from view. Trainees can search for SNM concealed on pedestrians (or a phantom), in packages, and in vehicles. To establish confidence, the check source can be concealed in some cases and omitted in others. Practice can be continued until each trainee is confident that a thorough search has been done, whether or not something is detected.

Both the instructor and the trainees can benefit from practice. The trainees learn what it takes for effective monitoring, and the instructor learns how effective his teaching has been. Another beneficial experience for both trainees and instructors is to visit operating locations where automatic monitors and hand-held monitors are being used. This may be the only practical training location for demonstrating the use of the automatic monitors.

Training should be provided initially for all new operators and periodically thereafter to all operators. In addition to training, periodic evaluation of how well operators are performing on the job can provide information on whether the training is effective and whether the frequency of periodic training is adequate.

25 Paul E. Fehlau, "Comparing a Recursive Digital Filter with the Moving-Average and Sequential ProbabilityRatio Detection Methods for SNM Portal Monitors," IEEE Trans. Nucl. Sci., Vol. 40, No. 2, pp. 143-146, 1993. 


\section{CALIBRATION, MAINTENANCE, AND TESTING}

Much of the information provided in this series of applications guides (Refs. 2-4) and additional information on using the monitors, such as on calibration, maintenance, and testing, is now available in a series of American Society for Testing and Materials (ASTM) standard guides discussed in the following sections. Standard guides in the series are published by the ASTM in its Annual Book of ASTM Standards, Volume 12.01. The ASTM does not number its standards in groups, so the SNM monitoring standard designations all begin with a $\mathrm{C}$, but that is followed by three or four usually out of sequence numbers and then a dash followed by a two digit designation of the year the most recent version was published. The current volumes of the Book of ASTM Standards are usually available in research libraries. Copies of the current editions of individual standards can be obtained at a nominal cost directly from ASTM. ${ }^{26}$ A copy of a custom booklet of Selected ASTM Standards on the Application, Evaluation and Maintenance of SNM Portal Monitors (current as of 1993) is available ${ }^{27}$ from Los Alamos for DOE users of the equipment.

\section{A. Applications Guidance}

Introductory information on selecting, installing, and using SNM monitors is covered by ASTM Guide C1112-93, "Standard Guide for Application of Radiation Monitors to the Control and Physical Security of Special Nuclear Materials." In addition to the introductory information mentioned, schedules for calibration and testing are discussed. Repair is recommended on an asneeded basis for any malfunctions that arise, and periodic calibration is recommended after repair as well as on a quarterly schedule. Calibration is always followed by performance tests that preferably use SNM test sources and procedures described in other ASTM guides. Additional functional testing is also recommended on a daily or shift change-basis, but this is a simple test that can use an isotopic source instead of SNM.

\section{B. Calibration Guidance}

The fundamentals of calibration are the same for every type of SNM monitor. Only the particulars may be different for different types of monitor and for different manufacturers. What is involved in calibration is checking or adjusting the energy response of a monitor's detectors to provide a uniform response and checking or setting parameters in the monitor's detection logic for optimum performance. The ASTM Guide, ASTM C1189-95 "Standard Guide to Procedures for Calibrating Automatic Pedestrian SNM Monitors," describes the procedures for the calibration of both detectors and detection logic. Although the title seems to limit applicability to pedestrian monitors, most of the information applies to vehicle monitors as well.

Ideally, manufacturer's manuals would be the primary reference for calibration of an SNM monitor. However, information particular to calibrating for SNM detection may not be familiar to manufacturers because they do not routinely service monitors used for that purpose in plants and may not be familiar as one would hope with SNM and how their monitor responds to it. The

26 ASTM, 100 Barr Harbor Dr., W. Conshohocken, PA 19428-2959 (610-832-9500) and request customer services.

27 Request the custom booklet of SNM monitor standards from D. A. Close, Group NIS-6, MS J562, Los Alamos National Laboratory, Los Alamos, NM 87545 (505-665-5923) or E-mail dclose@lanl.gov. 
ASTM calibration guide provides examples of detector response to SNM and other details of calibration that can be helpful to both manufacturers and users.

\section{Testing Procedure Guidance}

The ASTM testing procedures are outlined in a series of guides for evaluation of SNM monitor performance. These procedures are based on binomial tests (ones that have a yes or no result) of whether the SNM monitor can detect a particular test source with at least 0.5 probability. The number of iterations of each test in an evaluation is prescribed so as to give confidence that the outcome of the evaluation could be duplicated in $95 \%$ of repetitions of the evaluation. The advantage to this sort of evaluation over informal testing is that the result means something and can be reproduced.

The evaluation procedure for hand-held SNM monitors is prescribed in ASTM Guide C 123793, "Guide for In-Plant Performance Evaluation of Hand-Held SNM Monitors." This guide has a useful first Appendix that reproduces the original procurement performance specification for this type of SNM monitor. That specification is a dynamic one in which the monitor must detect the SNM test source as it is moving by at high rate of speed and at a distance from the monitor. However, for in-plant evaluation, the procedure was greatly simplified to one where the monitor is simply moved toward a test source until it alarms. The distance between the monitor and test source is then gauged against a predetermined minimum distance for successfully passing the test (yes) or not (no). This procedure is repeated a prescribed number of times, and then the results, (numbers of yes and no) are compared against a prescribed criterion for acceptance or rejection of the monitor's performance.

Testing procedures for vehicle SNM monitors are covered in ASTM Guide C 1236-93 "Guide to In-Plant Performance Evaluation of Automatic Vehicle SNM Monitors." This procedure is more realistic and involves actually driving a prescribed vehicle into and out or through a vehicle monitor while transporting an SNM source. Passages without a source are also required in a separate part of the evaluation to rule out chance detections, and the nuisance alarm history of the monitor is also reviewed. The results of the passages with SNM are recorded, detect ed or not detected, and compared with acceptance and rejection criteria.

\section{PART III \\ VEHICLE SNM MONITOR CATALOG}

In this part, you will find a description of the prospective capabilities of various vehicle SNM monitors, including both commercially available vehicle SNM monitors and prototypical concepts for new ones. Following that, the various commercially available monitors are described. 


\section{VEHICLE SNM MONITOR SENSITIVITY CATEGORIES}

\section{A. Historical Performance Categories}

Vehicle monitor worst-case performance categories were established in the mid-1980s for the original Los Alamos vehicle monitor applications guide (see Ref. 3) and are reproduced here in Table II. Note that these results are for a particular vehicle in a particular environment and consequently serve only to compare the relative performance of the different types of monitor designs, operating in their usual manner. Note also that monitors have evolved in the ensuing years and present-day monitors may perform differently.

Table II. Worst-case mass detection sensitivity in SNM vehicle monitors.

\begin{tabular}{|c|c|c|c|}
\hline \multicolumn{4}{|c|}{ Minimum Detected Mass ${ }^{a}$} \\
\hline $\begin{array}{c}\text { Vehicle Monitor } \\
\text { Type }\end{array}$ & $\begin{array}{l}\text { Low-Burnup } \\
\text { Plutonium (g) }\end{array}$ & $\begin{array}{c}\text { HEU } \\
(\mathbf{g})\end{array}$ & $\begin{array}{c}\text { Statistical False- } \\
\text { Alarm Rate }\end{array}$ \\
\hline Hand-held & $3-9$ & $100-300$ & $1 / 100$ \\
\hline Vehicle portal & 10 & 1000 & $1 / 4000$ \\
\hline Monitoring station & 0.3 & 40 & $3 / 1000$ \\
\hline \multicolumn{4}{|c|}{$\begin{array}{l}\text { ander worst-case conditions in a 1-ton van that is stationary except in the } 5 \text {-m-wide portal } \\
\text { where it travels at } 8 \mathrm{~km} / \mathrm{h} \text {. Background intensity is } 20 \mu \mathrm{R} / \mathrm{h} \text {, and shielding by vehicle } \\
\text { structures is highly significant. Detection implies a detection probability of } 50 \% \text { or greater. } \\
\text { Better performance is obtained under routine circumstances. }\end{array}$} \\
\hline \multicolumn{4}{|c|}{ b Statistical rates are for an empty monitor. } \\
\hline
\end{tabular}

One point to note about the table is that the hand-held monitor sensitivity is for a typical situation using a prescribed method of searching a vehicle, taking only a few minutes for the search. In other cases where the hand-held SNM monitor is used to follow up after an alarm in an automatic monitor, it is likely that greater sensitivity can be obtained. The reason for this is that the operator's suspicions have been aroused, and there would be little constraint on the time used for searching. Hence, repeated searching and searching at closer distances from suspect locations, both of which can increase sensitivity, can be expected to occur.

Another point to note about the table is that actual nuisance alarm rates for clean vehicles may be much lower than indicated in the table because vehicles occupying the monitor generally lower the monitor's count rate substantially. As a result, nuisance alarm rates from statistical variation are rare in automatic vehicle monitors. On the other hand, there is a new class of nuisance alarms that arises because of the high sensitivity of the monitors. Such things as plating out of uranium daughters from petroleum products can provide enough gamma rays to alarm a monitoring station, for example, when a propane truck is monitored. Dump trucks transporting clean soil can also alarm a monitor when the soil contains environmental uranium, potassium, and thorium in natural quantities. 


\section{B. Recent Performance Estimates}

\section{Performance Estimates for a Neutron Vehicle Portal Monitor}

Performance estimates were recently completed for the Los Alamos-designed Neutron Vehicle Portal Monitor. The monitor was constructed and evaluated in the late 1980s and the evaluations included static measurements and in-plant performance testing. The recent work ${ }^{28}$ examined the effects of varying the monitor's geometry, its operating parameters, and its location, and used the results to predict the monitor's performance under different circumstances. The work then used the static measurement results to predict the monitor's performance at the in-plant testing location, and the results agreed well with the testing results. The methods developed also were used to predict the monitor's performance under different circumstances, and four examples are listed in Table III.

The estimates in the table are based on drive-through monitoring at $8 \mathrm{~km} / \mathrm{h}(5 \mathrm{mph})$, and the monitoring logic is adjusted to give two good chances for detection during passage. The listed source strengths are the amounts needed for 0.5 probability of detection. They can be compared to Table II values by using an emission rate of 60 neutrons/s per gram of plutonium to convert the listed source strengths to mass of low-burnup plutonium. The examples in the table show a small improvement in sensitivity when the nuisance alarm rate is relaxed, and they show significant improvements from reducing the portal width and operating at lower altitude. The significance of altitude arises from fewer cosmic ray produced neutrons being present at lower altitudes, hence the monitor background count rate is lower. Of course, altitude is usually not a variable that can be controlled; however, it is something to be aware of when comparing the performance of monitors at different locations.

Table III. Performance examples for a neutron vehicle portal monitor.

\begin{tabular}{|l|l|c|c|}
\hline $\begin{array}{c}\text { Monitor } \\
\text { Information }\end{array}$ & \multicolumn{1}{|c|}{ Logic } & $\begin{array}{c}\text { Source Strength for } \\
\text { 0.5 Detection Probability }\end{array}$ & $\begin{array}{c}\text { Statistical Alarm } \\
\text { Rate (1/passages) }\end{array}$ \\
\hline $\begin{array}{l}7.32 \mathrm{~m} \text { wide, at } \\
2054 \mathrm{~m} \text { altitude }\end{array}$ & $\begin{array}{l}\text { Four 1-s interval moving } \\
\text { average, 2 chances }\end{array}$ & 9919 neutrons/s & $1 / 8333$ \\
\hline $\begin{array}{l}7.32 \mathrm{~m} \text { wide, at } \\
2054 \mathrm{~m} \text { altitude }\end{array}$ & $\begin{array}{l}\text { Four } 1-\mathrm{s} \text { interval moving } \\
\text { average, 2 chances }\end{array}$ & 8679 neutrons/s & $1 / 1500$ \\
\hline $\begin{array}{l}5.49 \mathrm{~m} \text { wide, at } \\
1117 \mathrm{~m} \text { altitude }\end{array}$ & $\begin{array}{l}\text { Four } 1-\mathrm{s} \text { interval moving } \\
\text { average, 2 chances }\end{array}$ & 4245 neutrons/s & $1 / 1500$ \\
\hline $\begin{array}{l}3.66 \mathrm{~m} \text { wide, at } \\
0 \mathrm{~m} \text { altitude }\end{array}$ & $\begin{array}{l}\text { Four } 1-\mathrm{s} \text { interval moving } \\
\text { average, 2 chances }\end{array}$ & 1823 neutrons/s & $1 / 1500$ \\
\hline
\end{tabular}

\section{Performance Estimates for an Expanded SNM Vehicle Portal}

The sensitivity for the vehicle portal listed in Table II is considerably less than the sensitivity for the vehicle monitoring station. However, this reflects their original applications: the vehicle monitoring station for detecting small amounts of HEU in stationary vehicles, and the vehicle portal monitor for detecting small amounts of low-burnup plutonium in moving vehicles. Recently,

28 P. E. Fehlau, D. A. Close, K. L. Coop, and R. L. York, "Estimated And Observed Performance Of A Neutron SNM Portal Monitor For Vehicles," Los Alamos National Laboratory document LA-UR-96-3904, September 27, 1996. 
an expanded vehicle-portal-monitor concept was examined ${ }^{29}$ for possible application to meeting the need for high-traffic-flow vehicle monitoring to detect HEU with minimum delay and at a reasonable cost. The likely applications for such a monitor are to protect SNM at Former Soviet Union storage facilities and to detect movement of SNM across national boundaries.

The new concept draws on the strong points of both monitor types. In its final form, the expanded monitor combines two vertical detector cabinets beside a roadway, as in a vehicle portal, with one below-vehicle detector cabinet across the roadway. A prototype monitor was assembled using commercial detector units from SNM portal monitors to estimate its performance. A fourth overhead detector unit was initially used as well, but was eventually rejected as providing minor improvement at a substantial cost. The prototype was used to measure background reduction profiles for a clean vehicle and source response profiles for the same vehicle containing a standard HEU source in each of three positions in the vehicle. Data profiles were recorded for the individual detector units, and both individual and combined data were analyzed to determine the amount of HEU required for detection with 0.50 probability during an $8 \mathrm{~km} / \mathrm{h}$ passage. Each analysis used an alarm threshold adjusted to give a nuisance alarm rate from counting statistics of 1 per 1000 passages.

The results in the table show a definite improvement in sensitivity by adding the lower (or lower and upper) units to a pair of roadside detectors. These combinations may result in satisfactory performance at a reasonable cost for some specific applications. However, note that the results in Tables II and III are not directly comparable because the test vehicles, source positions, and nuisance alarm rates were not identical. Hence, the original vehicle portal (Table II) may itself have performed differently under the present circumstances (Table IV).

\section{Table IV. HEU Sensitivity for combinations of vehicle portal monitor detector units.}

\begin{tabular}{|l|c|c|}
\hline \multicolumn{1}{|c|}{ Monitor Detector Combination } & $\begin{array}{c}\text { HEU Sensitivity } \\
\text { Range }^{30} \mathbf{( K g )}\end{array}$ & $\begin{array}{c}\text { Nuisance Alarm } \\
\text { Rate (per passage) }\end{array}$ \\
\hline Side units only & 1.0 to 0.17 & $1 / 1000$ \\
\hline Side plus lower unit & 0.19 to 0.03 & $1 / 1000$ \\
\hline Side plus lower and overhead units & 0.16 to 0.04 & $1 / 1000$ \\
\hline Lower and overhead units (no side units) & 0.52 to 0.02 & $1 / 1000$ \\
\hline
\end{tabular}

29 R. L. York, D. A. Close, and P. E. Fehlau, "An Optimized International Vehicle Monitor," Los Alamos National Laboratory document LA-UR-96-4505.

30 The sensitivity range for the three source positions used for testing. 


\section{COMMERCIALLY AVAILABLE VEHICLE SNM MONITORS}

\section{A. Hand-Held Monitors}

\section{TSA PRM-470A}

The original vehicle SNM monitor guide (Ref. 1) briefly described three hand-held monitors that were commercially available for SNM monitoring in 1987. By 1990, the updated pedestrian monitor guide (Ref. 4) described updates for this type of monitor, and one of them is still commercially available. This is the TSA Systems, Ltd. , ${ }^{31}$ model PRM-470A (Fig. 11), which evolved from the original Los Alamos Programmable Radiation Monitor. It is designed for use as a hand-held SNM monitor and weighs about $1 \mathrm{~kg}(2.4 \mathrm{lb})$; its detector is small and its detection logic is designed for rapid hand searches.

The latest version of the monitor, PRM-470A(P), was evaluated at Los Alamos in $1992 .{ }^{32}$ This version of the instrument uses a small plastic scintillation detector instead of the original $\mathrm{NaI}(\mathrm{Tl})$ detector. The original detector is still available in the more expensive PRM-470A(NaI) version. The benefit of using the plastic scintillator is that it has some neutron sensitivity; the cost of using plastic is that it has lower sensitivity for detecting HEU. Another change in the instrument is its use of a variable multiplier for the number of standard deviations used in calculating an alarm threshold. Internal switches are set to 4 standard deviations at the factory.

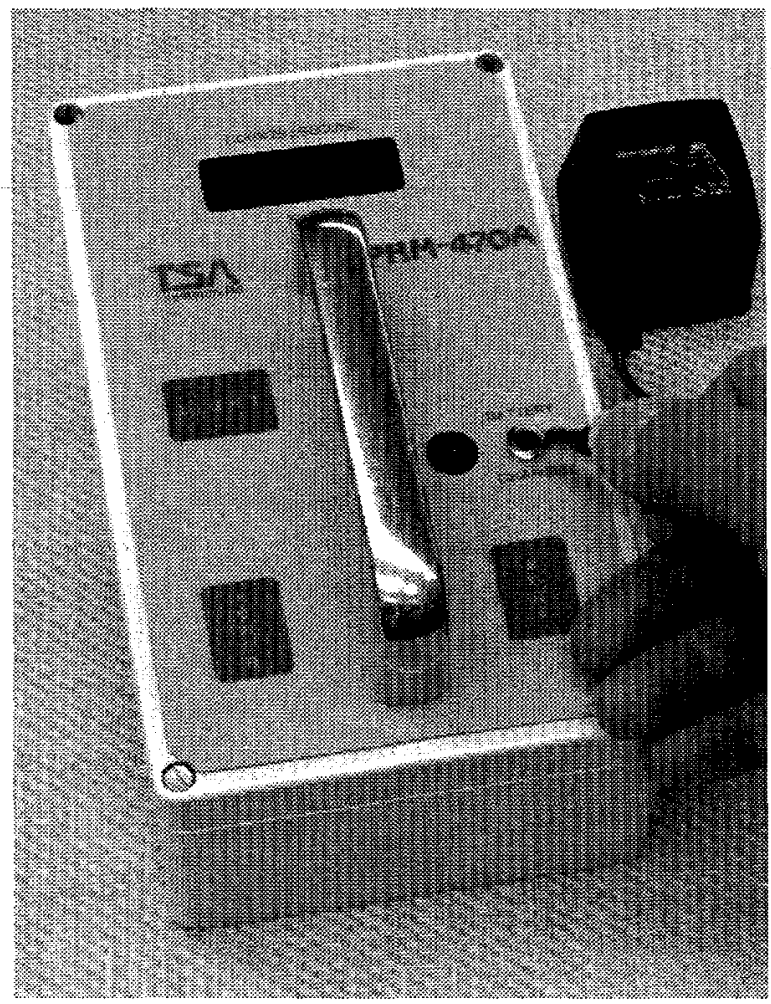

Fig. 11. The TSA Systems, Ltd., model PRM-470A(P) hand-held SNM monitor.

31 TSA Systems, Ltd., 1830 Boston Avenue, Longmont, CO 80501 (303-651-6147).

32 Paul E. Fehlau, "Report on a Brief Evaluation of the PRM-470A Hand-Held SNM Monitor," Los Alamos National Laboratory memorandum N2-92:679PEF to Nick Nicholson, June 15, 1992. 
Our evaluation of the monitor was based on published criteria ${ }^{33}$ for evaluating hand-held SNM monitors. We found that the PRM-470A(P) met performance criteria for detecting plutonium but not for detecting HEU using the factory setting of 4 for the number of standard deviations used to calculate the alarm threshold. We found that when using the PRM-470A(P) for detecting HEU, the multiplier must be set to 3 standard deviations to achieve the required sensitivity. This information has not appeared in the manufacturer's manual but it is important information that should be conveyed to users. The cost of using the lower threshold should be insignificant for hand-held monitoring where only repeated alarms are significant indicators for detection of SNM.

A final note on the PRM-470A is that production of the microprocessor used in it has been discontinued. TSA will be able to support old units but will use a different processor in new units as of about April 1997. Instruments having the new control board and processor will be designated PRM-470B.

\section{B. Vehicle SNM Portal Monitors}

The vehicle SNM portal monitor in the original guide (Ref. 1) that has had most commercial success is the TSA Systems, Ltd., VM-250 (called VMC-250 in the earlier guide). It is still offered for sale today using the same illustration that appears in the original guide. But the VM-250 has changed over the years. The other commercially available vehicle portal monitor is the Canberra Industries JPM-12A, which is a development that results from an early collaboration between Los Alamos and Jomar Systems (now part of Canberra Industries, Inc.$^{34}$ ) in developing another monitor in the original guide called the Los Alamos Vehicle SNM Portal Monitor.

\section{TSA Systems, Ltd., VM-250 Vehicle Portal Monitor}

The VM-250 evolved from a TSA Systems involvement with Los Alamos in producing an Entry Control Monitor for vehicles that is listed in the original guide. TSA adopted low-power electronics that could be housed in the detector cabinets of the VM-250, reducing its cost and making it much easier to install.

We worked with TSA Systems in recent years to improve the SC-750 control unit to reduce electronic noise and allow the monitor to operate with lower alarm thresholds, thereby improving its sensitivity. ${ }^{35}$ TSA has recently adopted other features of early Los Alamos monitors by providing optional cabinet heaters and insulation for operation in cold environments. Finally, TSA has recently renovated the system controllers that provide the monitor's operating and control electronics. The new SCA-755 and SC-725 controllers and a TSA-produced Windows program offer downloading of setup parameters from a personal computer and uploading of stored background and alarm data from the controller.

33 See Appendix X1 of ASTM C 1237-93, Standard Guide to In-Plant Performance Evaluation of Hand-Held SNM Monitors.

34 Canberra Industries, Inc., 800 Research Parkway, Meriden, CT 06450 (203-238-2351).

35 Paul E. Fehlau, "A Portable, Automatic SNM Monitor for Nuclear Safeguards: Development, Evaluation, and Applications," Los Alamos National Laboratory report LA-12626-MS (September 1993). 
Another form of the VM-250 is being offered by TSA. The VM-375 is an extension of the basic vehicle portal monitor by adding a third detector below or above the vehicle path. There is no standard form for this monitor, and it could be used with either of two positions for the third detector and with detection logic that varies from monitoring individual detectors to monitoring the sum of the signals from all three. Los Alamos recently mocked up the possibilities (Fig. 12) and evaluated their performance as discussed below and in Sec.I.B.2 of this part.

The TSA VM-250 in its present commercial form (SCA-755 and SC-725 controllers) has not undergone a formal evaluation. The most recent work at Los Alamos used the SC-750 controller series and arranged VM-250 detector units to form a standard portal with added detectors overhead and at ground level as illustrated in Fig. 12. Analysis of measurement results (see Table IV) indicated that the best option for highest sensitivity was using the combination of the side and lower detectors shown in the figure. The calculated performance is based on the expected nuisance alarm rate for the controller used (SC-750), and best sensitivity was obtained by summing detector signals for analysis. Using the three detector combination with lower detector provided a five-fold increase in mass sensitivity for HEU over the conventional portal arrangement of side detectors.

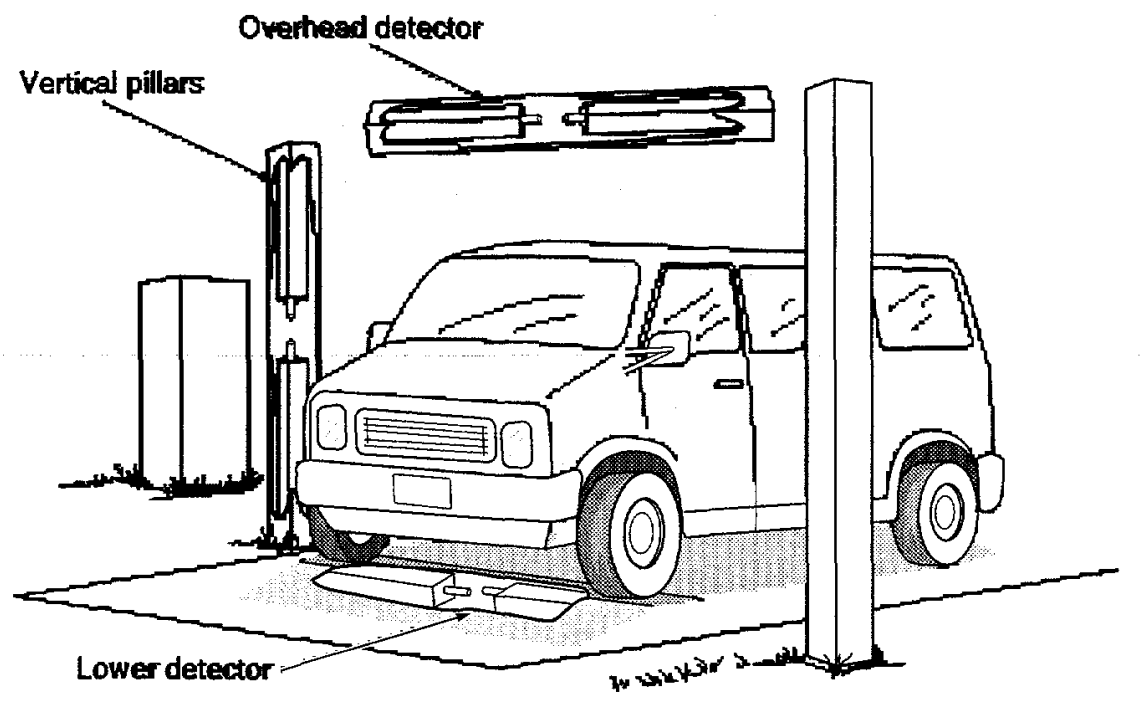

Fig. 12. The four detector configuration using TSA VM-250 components.

\section{Canberra JPM-12A Vehicle Portal Monitor}

The SNM monitor expertise at Canberra stems from their acquiring Jomar Systems of Los Alamos, a small safeguards equipment manufacturer. Jomar had collaborated with us in developing control modules for portal monitors and other related instruments, and Jomar produced the Los Alamos-designed vehicle SNM monitoring stations used in Los Alamos. The Canberra JPM-12A vehicle portal monitor is Canberra/Jomar's first attempt at such a monitor, and they have adopted the self-contained approach pioneered by TSA Systems. We had our first opportunity to evaluate the technology used in the JPM-12A in an evaluation of their related new JPM-21A pedestrian portal monitor. ${ }^{36}$

36 Rob L. York, "Evaluation of the Canberra JPM-21 A Pedestrian Monitor," Los Alamos memorandum NIS-696:0178RY to distribution, March 29, 1995. 
Our evaluation of the JPM-21A determined that its performance met the requirements for a Category II SNM portal monitor (detected 10-g HEU sphere with probability of 0.5 or greater as prescribed in ASTM Standard Guide C 1169-9137) at a nuisance alarm rate of 0.001 per passage or less. However, the report notes that adequate performance could not be obtained using the manufacturer's operating manual and that changes in the monitor were necessary to obtain a lower discriminator level for detecting radiation from HEU. Several changes for production monitors were suggested with the expectation of a future follow-on evaluation of the JPM-12A vehicle portal monitor.

The JPM-12A now appears in Canberra sales literature. The reported performance is based on the original Los Alamos prototype monitor and not on an evaluation of the JPM-12A. Figure 13 reproduces Canberra's expectation for a typical installation of the monitor.

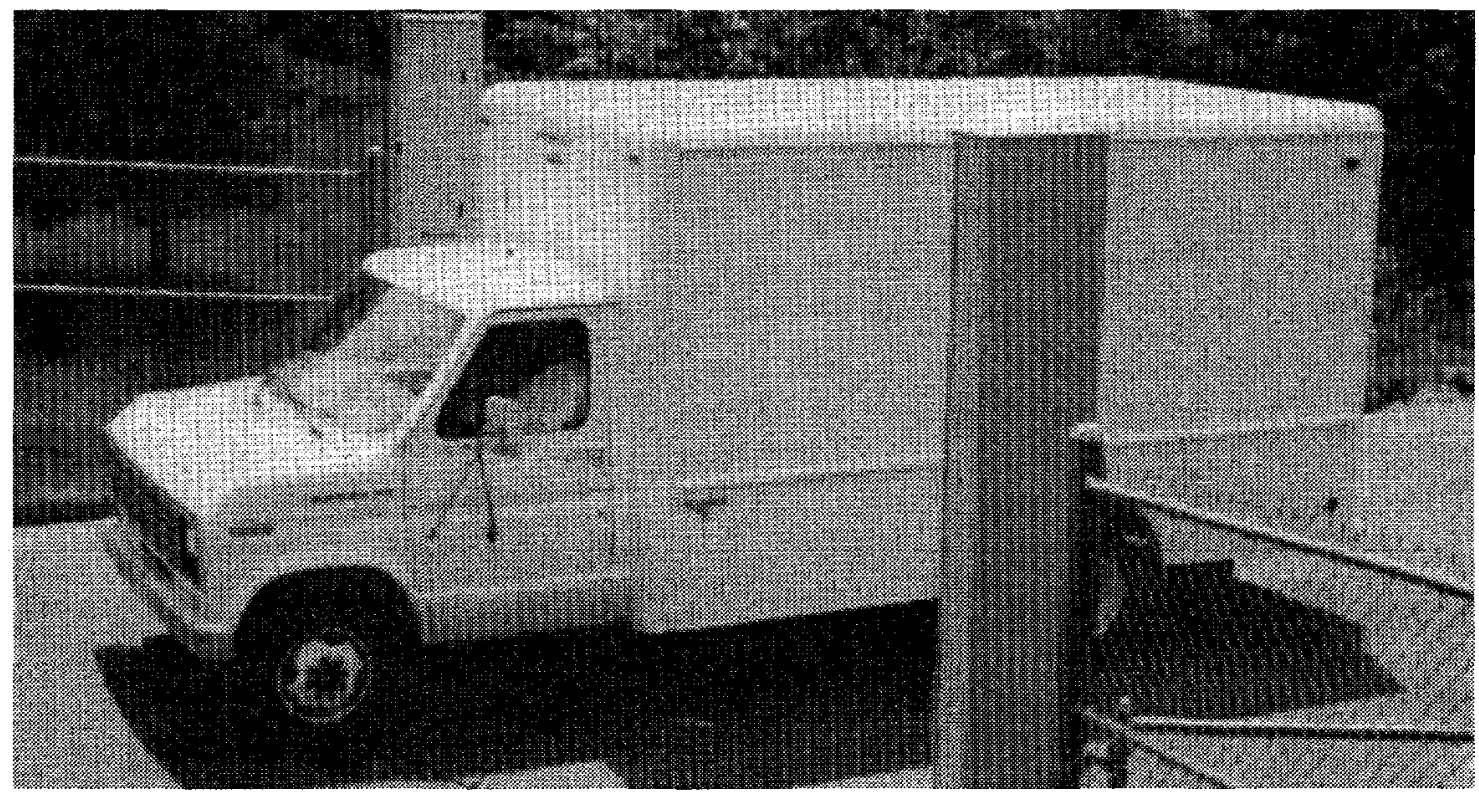

Fig. 13. The Canberra JPM-12A Vehicle Portal Monitor sales illustration.

\section{Canberra JPM-31A Neutron Vehicle Portal Monitor}

Only the basic technology for neutron portal monitors for vehicles was discussed in the original guide, and the monitors were introduced in this report in Part I, Sec. IV.D. The Los Alamos prototype neutron vehicle portal monitor is illustrated in Fig. 4, and only one such portal has since been produced commercially. That monitor was produced by Canberra for use as an emergency exit monitor for a plutonium facility, and Canberra offers it as a vehicle portal monitor as model JPM-31A. This neutron monitor has not been evaluated by us as an emergency-exit monitor or as a vehicle SNM portal monitor. Canberra offers it as a standard neutron portal and in combination with plastic scintillators (JPM-32A) as an integrated gamma-ray and neutron portal monitor.

37 ASTM C 1169-91, Guide for Laboratory Evaluation of Automatic Pedestrian SNM Monitor Performance (1991). 


\section{Related Vehicle Portal Monitors}

As mentioned in Sec. IV.C.1 of Part I, another application for vehicle monitors is to detect radioactive materials contained in scrap materials entering steel mills. These monitors are used to monitor rail cars and trucks that transport scrap. The monitors are similar to SNM monitors in that they measure background when unoccupied, establish an alarm threshold, and then monitor vehicles when present (and sound an alarm if necessary). The difference in their primary application is that their target for detection is a fairly intense source having a $1 \mathrm{mR} / \mathrm{h}$ or greater exposure rate at its container surface and the area to be monitored is limited to the area containing scrap.

\section{Ludlum Measurements, Inc. ${ }^{38} \mathbf{3 5 0 0}$ Gate Monitor (For the Scrap Industry)}

The Ludlum 3500 monitor is illustrated in Fig. 6. The detectors shown in the figure are large $\mathrm{NaI}(\mathrm{Tl})$ scintillators that are housed in rectangular boxes inside the pipe frame supports beside the vehicle. Other models use plastic scintillators. The monitor's microprocessor system can control up to eight detectors, and it is designed to detect small changes in radiation level. Visual display is used to convey information on detector readings, location of alarms, vehicle speed, and diagnostic information. The vehicle speed is pertinent to assuring that passage speed is in the expected range for the desired sensitivity. Sales literature information on sensitivity shows detecting a $1 \mathrm{mR} / \mathrm{h}$ source located at the center of the load (nominal scrap density) with greater than 0.9 probability with the detectors spaced $60 \mathrm{~cm}$ from the sides of the vehicle. Although this monitor is not designed for SNM detection, its measurement of vehicle speed and display of counting information would be useful for some SNM monitoring applications.

\section{Bicron Corp. ${ }^{39}$ ASM 6000 Steel Scrap Monitors}

The Bicron steel scrap monitors evolved from their experience at manufacturing plastic scintillation detectors for SNM monitors. Their monitors are intended for monitoring motor vehicles or rail cars, as illustrated by the entry station photograph in Fig. 14. The monitor uses large area plastic scintillation detectors located in the transverse cabinets located at truck bed height in the figure. The monitor can be used for drive-through or wait-in monitoring. The monitor also measures vehicle speed (6000-E version) and will alarm on excessive speed as well as indication of radioactive material. The monitor's controller also does self-diagnostics to increase reliability. Quoted sensitivity for the $1 \mathrm{mR} / \mathrm{h}$ exposure rate source is detection at $8 \mathrm{~km} / \mathrm{h}(5 \mathrm{mph})$ passage speed.

38 Ludlum Measurements, Inc., P. O. Box 810, Sweetwater, TX 79556 (915-235-5494).

39 Bicron Corporation, 12345 Kinsman Road, Newbury, OH 44065 (261-554-2251). 


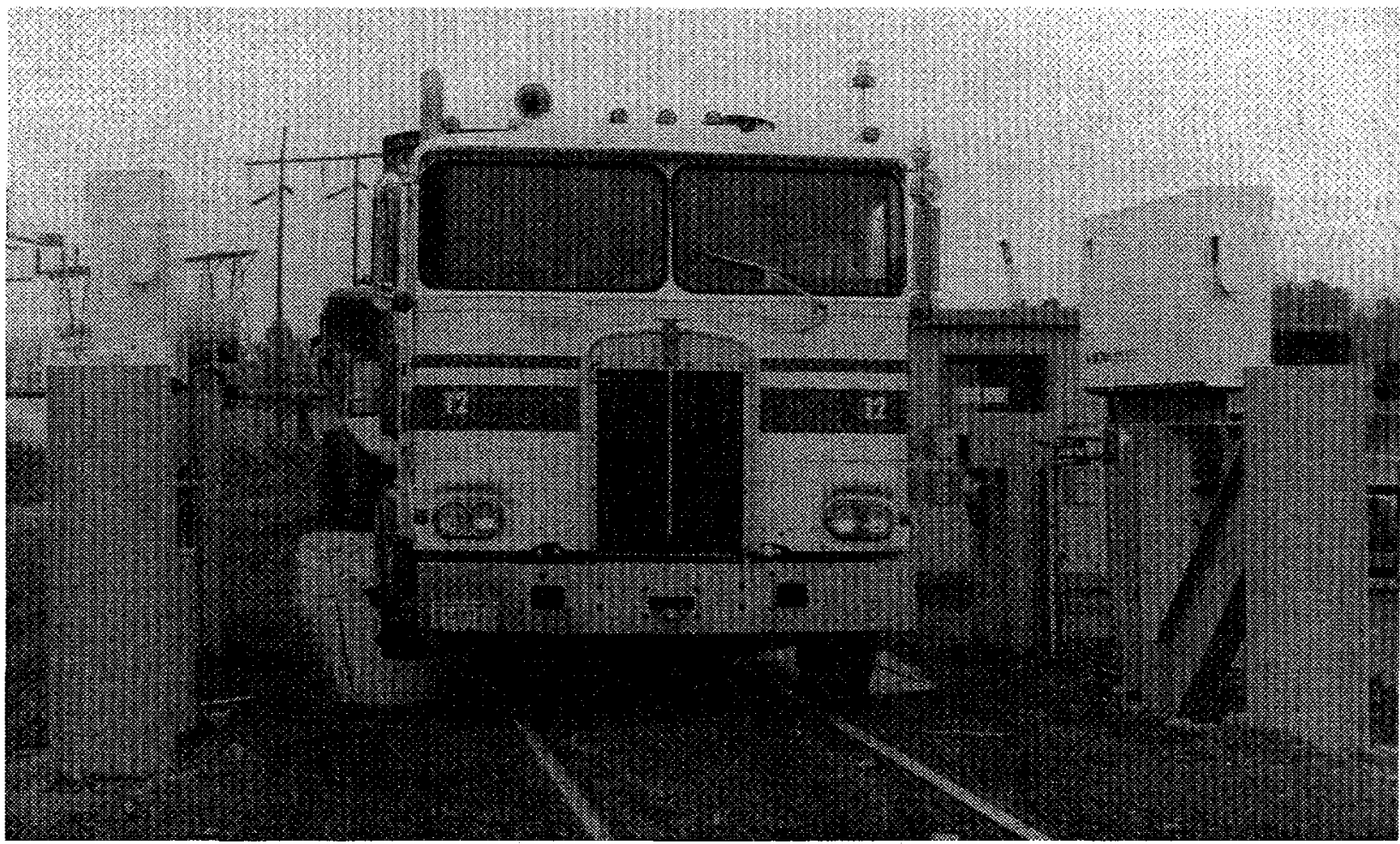

Fig. 14. The Bicron Corp. ASM 6000 Monitor.

\section{Vehicle SNM Monitoring Stations}

The original Los Alamos SNM Vehicle Monitoring Station illustrated in Fig. 5 is still the basis for commercially available stations, and Canberra Industries presently offers a JPM-11A version of the original. Sales literature for the JPM-11A implies that the original nuclear instrument module (NIM) electronics is still being used, so performance similar to the Los Alamos JOMAR monitors installed at Los Alamos might be expected. Performance cited in the sales literature is for the early Los Alamos prototype using NIM electronics. However, future sales of the JPM-11A may involve using the low-power electronics implemented in the JMP-12A pedestrian monitor (see Sec. II.B.2 of this part).

\section{ACKNOWLEDGMENTS}

We are indebted to T. E. Sampson of Los Alamos for the information reproduced in Table I. We also appreciate the help provided by members of Group NIS-6 in our development and evaluation of SNM monitors. We also thank the manufacturers who provided monitors for evaluation and sales literature. 


\section{GLOSSARY}

\section{Alarm Increment}

A quantity added to the average background count during monitoring to establish an alarm threshold. For example, alarm thresholds are often background plus an alarm increment equal to 4 standard deviations of the background $\left(B+4 \mathrm{~B}^{0.5}\right)$.

\section{Alarm Threshold}

A quantity compared with monitoring results to establish whether or not to sound an alarm.

\section{Detection Efficiency}

There are two distinct terms. Intrinsic detection efficiency is a quantity indicating the percentage of individual gamma rays or neutrons that are intercepted by a radiation detector that are actually detected and counted. Total detection efficiency is a quantity indicating the percentage of all of the gamma rays or neutrons emitted by a source that are actually detected and counted.

\section{He (Helium 3)}

The helium isotope having a mass number of 3 . Helium- 4 is the common form of helium. Helium-3 is not common, but is plentiful enough to be commonly used in neutron proportional counters where its nuclear properties allow it to function as a thermal neutron detector.

\section{MAA (Material Access Area)}

An area that is protected to allow storing or working with special nuclear materials.

\section{$\mathrm{NaI}(\mathrm{Tl})$}

Thallium-Activated Sodium Iodide, or simply Sodium Iodide; an inorganic crystal used as a gamma-ray detector.

\section{NIM}

A standard for electronic modules. A bin is used to provide power to modules that slide into the bin. The signal-conditioning and power supply modules available from NIM suppliers are usually very well characterized and reliable.

PA (Protected Area)

A secure area that may contain one or more material access areas.

\section{Solid Angle}

This term is used to indicate the fraction of all radiation emitted by a point source that would be intercepted by a particular radiation detector. For example, $50 \%$ of all the radiation emitted by a point source positioned on the surface of a single detector would be intercepted by the detector. Moving the source away would decrease that amount.

\section{SNM (Special Nuclear Material)}

For our purposes, SNM is highly enriched uranium and all forms of plutonium. 


\section{Total Internal Reflection of Light}

When light strikes a solid material, part of it is reflected and part of it enters the material where it is absorbed. The converse is also true, light leaving a solid can be partially transmitted and partly reflected back into the solid. However, light trying to leave a solid at a small angle of incidence can be totally reflected back into the solid. This condition provides for efficient collection of light in long plastic scintillators, and is possible at the interface between a solid and air.

\section{Vehicle Trap}

A fenced area with entry and exit gates that encloses a vehicle being cleared for entry or exit from a facility. 